\title{
Vida y compromiso militante en los años setenta: la experiencia de la Organización de Izquierda Comunista (OIC)
}

\author{
JoEl SANS MOLAS \\ Grup d’Estudis sobre República i Democràcia \\ (GERD - Universitat Autònoma de Barcelona, España) \\ orcid.org/0000-0002-5930-7029
}

Presentación: 5 nov. 2018 | Aceptación: 20 nov. 2018 | Publicación: 15 des. 2018

Citación recomendada: Sans Molas, Joel. 2018. «Vida y compromiso militante en los años setenta: la experiencia de la Organización de Izquierda Comunista (OIC)». Dictatorships \& Democracies. Journal of History and Culture 6: 137-185. doi: https://dx.doi.org/10.7238/dd.voi6.3155.

Resumen: Durante los años setenta hubo en el Estado español una eclosión de organizaciones de la izquierda revolucionaria que tuvieron la capacidad de involucrar a miles de personas. Estas organizaciones desarrollaron un modelo de militancia de alto compromiso, que fue un activo para la movilización contra el franquismo, pero que también tuvo una repercusión personal ambivalente sobre los militantes. Analizamos aquí, a través del caso de la Organización de Izquierda Comunista, las características de este modelo de militancia, las motivaciones y aspectos de cultura política que la sustentaban, cómo lo vivieron las personas que formaron parte de ella y la relación compleja entre dimensión vital y política.

Palabras claves: izquierda revolucionaria, militancia, cultura política, franquismo, Transición

Life and Militant Commitment in the 7os: the Experience of the Communist Left Organization (OIC)

Abstract: During the 7os in the Spanish State there was an explosion of organizations of the revolutionary left, which had the capacity to involve thousands of people. These organizations developed a model of high commitment militancy, which was an asset for the mobilization against Franco regime but also had an ambivalent personal impact on the militants. In this article we analyse, through the case of the Communist Left Organization, the characteristics of this model of militancy, the motivations and aspects of political culture that supported it, how the people who took part in the organization experienced it and the complex relationship between politics and personal life. Keywords: revolutionary left, militancy, political culture, Francoism, Transition 
Desde finales de los años sesenta y, especialmente, durante los años setenta, se vivió en el Estado español la eclosión de una gran diversidad de organizaciones de la izquierda revolucionaria que tuvieron la capacidad de atraer e involucrar a miles de personas en sus filas. Más allá de la importancia cuantitativa de estas organizaciones - que supusieron, en su conjunto, la segunda fuerza de la izquierda después del PCE-, hay un aspecto de interés que trataremos en el presente artículo a partir de la experiencia de la Organización de Izquierda Comunista (OIC): la militancia de alto compromiso que desarrollaron con fuerza y que fue un activo para impulsar la movilización social y política, pero que también tuvo una repercusión personal sobre los militantes en sentidos ambivalentes. Ver las características de esta militancia, las motivaciones y aspectos de cultura política que la sustentaban y cómo lo vivieron las personas que integraron la OIC, son algunos de los aspectos que nos ayudarán a tener una comprensión más global del fenómeno de enorme intensidad y dedicación que fue la militancia radical de esos años.

A la hora de estudiar la militancia revolucionaria cabe tener en cuenta que los estudios sobre la izquierda bajo el franquismo han tenido poco en cuenta la izquierda radical, aunque en los últimos años se ha avanzado considerablemente sobre ello. ${ }^{1}$ Asimismo, el enfoque historiográfico sobre la izquierda ha privilegiado a menudo los aspectos más institucionales y los estrictamente políticos o ideológicos. Aún así, también se ha ido avanzando recientemente en trabajos que han prestado atención a la cuestión de la militancia, si bien hay una ausencia bastante general de estudios específicos sobre la militancia revolucionaria, excepto algunas excepciones destacadas. ${ }^{2}$ Por todo ello es útil tener en cuenta las aportaciones hechas por la historiografía sobre militancias de otras corrientes de la izquierda. En uno de estos trabajos, Juan Antonio Andrade Blanco

1 En los últimos diez años ha habido un creciente número de trabajos alrededor de otras corrientes de la izquierda, como la radical o revolucionaria, entre los que podemos destacar, entre otros: Wilhelmi (2016), Martín Ramos (2011), Caussa \& Martínez i Muntada (2014), Martínez i Muntada (2016), Molinero \& Ysàs (2016).

2 Véase David Beorlegui Zarranz, Transición y Melancolía. La experiencia del desencanto en el País Vasco (1976-1986) (Madrid: Postmetropolis, 2017). También la militancia ha recibido la atención con una mesa específica ( «La experiencia militante: memorias y trayectorias») en un reciente congreso dedicado a la izquierda radical (Fundación Salvador Seguí 2018, 201-296). 
reivindicaba la dimensión de la historia social y cultural, además de la política, para estudiar y comprender las organizaciones políticas (Andrade 2012a). Por otro lado, Giame Pala, en un artículo sobre el trabajo de los comunistas catalanes, analizaba los distintos aspectos que sustentan la intensa entrega militante: una concepción del mundo a través de una terminología específica, la orientación y formación política, la identidad propia, el estilo de militancia, los referentes históricos y vivientes ejemplificantes o los mitos que dan horizonte a la práctica diaria (Pala, 2013). Todos estos aspectos se mueven principalmente en el espacio del universo mental y son, sin duda, elementos claves para la comprensión de la militancia.

En este artículo sobre la militancia revolucionaria de la OIC, ${ }^{3}$ además de tener en cuenta aspectos que señalan estos autores, quiero aumentar la atención sobre elementos que se mueven más en el espacio del sentir de las personas, de sus motivaciones y anhelos, es decir, la dimensión vital, que a veces también se menciona en los estudios sobre militancia.

Nos podemos plantear: ¿Qué nos aporta tener esta visión más amplia y global de lo que significa la política? Por un lado, en general, va en línea con lo que considero una motivación fundamental: el estudio de la historia nos ha de ayudar a tener una comprensión más plena de lo que somos los seres humanos, y cómo - y por qué- cambiamos en el tiempo. Por otro lado, esto permite mirar hacia la persona y ver su sitio dentro de la historia. Es decir, tratar no solamente el colectivo - la organización política, la clase o el movimiento social - sino entender que este está conformado por personas. Claro está que no se trata de analizar la historia a partir de individuos aislados, sino de entender que la interacción entre sociedad o colectivo y persona se produce siempre en las dos direcciones, que se afectan mutuamente. Además, prestar una atención específica a la relación entre la dimensión vital y la política creo que añade una pieza más a la comprensión de por qué la gente se involucra en unas organizaciones - que crecen enormemente en un período-y por qué motivo pos-

3 Para la historia de la OIC y un mayor desarrollo de algunas de las cuestiones que se apuntan en este artículo, véase Sans Molas (2017b). 
teriormente - en el momento de la Transición — hay una desimplicación significativa, abandonando o reduciendo en muchos casos la militancia.

El enfoque de la militancia es muy relevante para aportar luz sobre la relación compleja entre política y persona, en la que se mezclan cuestiones que van desde las culturas políticas e identidades hasta las motivaciones, experiencias, sentimientos y motivaciones personales. Como defiende Juan Antonio Andrade:

El perfil sociológico de las militancias, su inserción en la sociedad, sus expectativas vitales, su cultura militante, la forma en que sienten su compromiso, la disposición de su tiempo vital al tiempo de militancia, sus niveles de formación teórica, sus sistemas de valores, su sentido de pertenencia a una tradición de la que forman parte o sus tendencias ideológicas, su identidad al fin y al cabo, son dimensiones que dan una imagen más completa y humanizada de los colectivos estudiados, y constituyen un campo de trabajo vastísimo y sumamente atractivo para el historiador. (Andrade 2012a, 124)

En cierta manera se trata de plantear que la adscripción política va más allá de una parte racional-intelectual asociada a un sistema de ideas ordenado y asumido conscientemente. A través de la política se vehiculan muchos aspectos del ser humano que superan lo estrictamente ideológico: inquietudes, anhelos, deseos, fidelidades, sentimientos, pulsiones vitales, relaciones sociales y de amistad... El compromiso político es también una forma, especialmente en la juventud, de desarrollarse y crecer personalmente, de descubrir el mundo y de posicionarse en él. Es por ello por lo que debates alrededor de conceptos como cultura política, religión política o sacralización de la política son interesantes, puesto que ayudan a asumir más aspectos que el puramente relacionado con las ideas de esta compleja relación entre persona y política. Nos abren la puerta a ver que la política va más allá de la racionalidad y que en buena parte la trasciende, recogiendo motivaciones más profundas.

Como se señala en un artículo sobre el activismo juvenil en Albacete, frente a la visión funcionalista de la política, la militancia «si bien no puede ser tildada de irracional tampoco respondió simplemente a la cruda y fría lógica del cálculo ascético entre costes y beneficios, pues en buena 
manera estuvo fundada en el compañerismo, confianza y solidaridad entre aquellos que compartían lo que entonces no alcanzaba sino la categoría del deseo» (Martín, González \& Ortiz 2009, 30). El artículo que presentamos se plantea ver la cuestión de la militancia de la OIC y su momento histórico desde la óptica de personas concretas. En cierta medida lo que propongo tiene relación con lo que David Beorlegui señala como la dimensión subjetiva de la militancia, en la que tiene peso una multiplicidad de cuestiones:

Se trata de explorar la dimensión subjetiva de la militancia concibiéndola como un proceso incesante de adquisición de significados por medio de determinadas formas, prácticas, emociones, discursos, aspiraciones y desengaños. (Beorlegui 2016, 11)

Para estudiar la cuestión de la militancia y su relación con las personas y su vida, las fuentes orales aparecen como la fuente privilegiada; son mucho más que un complemento a las fuentes escritas. Con ellas nos relacionamos con un material que no son objetos (como las fuentes documentales) sino personas, y que, por lo tanto, recuerdan, piensan, sienten, se emocionan y han ido cambiando - y lo continúan haciendo hoy- a lo largo del tiempo (Portelli 1991, 45). A su vez, las fuentes orales pueden dar voz a personas que normalmente no la tienen en la historia. También, como explica Paul Thompson, la historia oral «Introduce la vida en la historia y eso hace que se amplíen sus miras. Hace posibles los héroes no sólo entre los líderes sino entre la mayoría desconocida de gente» (Thompson 1988, 29).

Es, por lo tanto, una fuente esencial para adentrarnos en el pasado, ya que estamos hablando directamente con los que fueron protagonistas de aquello que pasó y nos podemos acercar a sus experiencias. Además, podemos interrogar a las personas desde múltiples ángulos, más allá del ideológico o de las propuestas políticas de la organización, lo que supone una fuente de riqueza increíble. Esto, al mismo tiempo, implica una complejidad evidente, por la multiplicidad de aspectos de cada persona - a lo que se suma la dificultad de cada uno de conocerse bien y de expresarse sobre el pasado - y también por su unicidad: cada persona habla des- 
de su propia experiencia y sensibilidad (Alted \& Mateos 1990, 59), lo que podría dar lugar a tantas visiones distintas como personas y que, además, podrían variar en función del momento en el que hablaran.

Sin embargo, a pesar de la complejidad que presenta contar con un número amplio de personas entrevistadas, ello ofrece una adición de testimonios individuales que posibilita establecer relaciones entre sí, ver perspectivas compartidas y distintivas, extraer conclusiones que van más allá de la persona individual y poder ver dinámicas de lo colectivo, es decir, se transforma en una «base para establecer generalizaciones» (Beorlegui 2016, 37). La complejidad de las fuentes orales, al mismo tiempo, nos aporta pistas sobre la naturaleza de las subjetividades, pues el «carácter complejo y múltiple que exhiben los testimonios» es «una virtud por su capacidad de informar de la naturaleza contingente y problemática de la subjetividad, así como de los cambios que esta experimenta en el tiempo» (Beorlegui 2016, 38).

Ver la historia oral con suspicacia, prefiriendo la tranquilidad y estabilidad de los documentos a la hora de explorar el pasado, creo que llevaría a una cierta paradoja. Queremos saber qué hicieron los humanos en el pasado, pero desconfiamos de los humanos que lo vivieron cuando se trata de que lo explican y de poder sacar conclusiones. Por el contrario, considero que el estudio de la persona en el pasado tiene que relacionarse ineludiblemente con esas mismas personas en el presente.

\section{Época de radicalización y militancia}

La izquierda revolucionaria desarrolló un tipo de militancia caracterizada por un alto compromiso personal hacia el partido y la causa, y una gran dedicación en tiempo; además, las tareas políticas impregnaban buena parte de la vida de la persona, desde las actitudes en el centro de trabajo y estudio hasta la decisión sobre el sitio donde vivir o el puesto de trabajo, en función de cómo ello podía contribuir a extender la labor política. Este tipo de modelo, de ser revolucionario "las 24 horas del día" o de militancia total, no era exclusivo de la izquierda radical, sino que también estaba presente en las filas del PCE-PSUC y, más en general, se encontraba en cierta forma en el ambiente del intensivo activismo antifranquista. El 
tipo de militancia de la OIC se desarrolló, con sus especificidades, dentro de este esquema, con unos contornos muy exigentes hasta 1977, cuando suavizó algunos aspectos y separó en mayor medida el ámbito familiar y personal del político. ${ }^{4}$

Hay varios elementos del momento que respaldaban el proceso de implicación política en la militancia revolucionaria. ${ }^{5}$ En primer lugar, el régimen franquista marcaba decisivamente la realidad española y las vivencias de los jóvenes que nacieron entre mediados de los años cuarenta y los años cincuenta, que son los que protagonizarán mayoritariamente el auge militante de los años setenta. Una militancia incentivada por la experiencia de ver la injusticia y precariedad de las condiciones laborales y de vida en fábricas y barrios. Además de la oposición a una determinada situación social, el marco autoritario y represivo del régimen terminaba de generar una indignación que llevaba a la politización e implicación. A ello cabe añadir que la ilegalidad de los partidos y la represión a la disidencia comportaba que hubiera grandes vacíos políticos y que, además, estos vacíos solo pudieran ser llenados desde fuera de la institucionalidad franquista existente. Miles de jóvenes empezaban a buscar ideas y espacios colectivos para vertebrar sus anhelos y ansias. La tendencia a la radicalización y a la politización hacia la izquierda era algo compartido que sucedía en paralelo desde distintos ámbitos. Dolors Igual, militante de la OIC, señala que este proceso se daba en los distintos espacios asociativos y culturales, los boy scouts o la HOAC: «en aquella època tot portava cap al marxisme». ${ }^{6}$ Una parte de esta corriente de inquietudes no se identificaba con el PCE-PSUC, por considerarlo un partido demasiado moderado, y buscaba alternativas en el maoísmo, el consejismo, el trotskismo o el anarquismo, entre otros.

En segundo lugar, hay que señalar también el gran peso que tuvo el marco internacional. La militancia revolucionaria se debe inscribir dentro de un fenómeno más general de radicalización política y rebeldía social a escala mundial desde finales de los años cincuenta hasta finales de los años

4 Aspectos más desarrollados en Sans (2016 y 2017a).

5 Los motivos para implicarse a militar en la OIC están tratados en Sans (2016).

6 Entrevista realizada por Joel Sans a Dolors Igual (militante universitaria y vecinal de la OIC en Valencia), Castelló, 22 de junio de 2016.

DICTATORSHIPS \& DEMOCRACIES 6 (2018) · EISSN: 2564-8829 · PUNCTUM, UNIVERSITAT OBERTA DE CATALUNYA \& FUNDACIÓ CARLES PI I SUNYER 
setenta. ${ }^{7}$ El auge de esta militancia es un fenómeno que abarca, al menos, los distintos países del mundo occidental y que transcurre íntimamente relacionado con un ambiente de rebeldía juvenil que se expresa también en fenómenos como la contracultura, el movimiento hippie, los llamados nuevos movimientos sociales y cambios grandes en la forma de vida y de expresión de actitudes. Hay una ruptura de equilibrios sociales y formas de comportamientos previos en los años sesenta y setenta, prefiguradas con algunos aspectos ya en los cincuenta. Se trata de nuevas actitudes, muchas veces poco vertebradas orgánicamente, que surgen a partir de relaciones informales o de espacios de sociabilización, vinculados a la cultura y el ocio, con un funcionamiento más autónomo y menos reglado, lo que en buena medida es una novedad histórica.

Además, la izquierda revolucionaria era una izquierda internacionalista que analizaba lo que pasaba alrededor del mundo buscando experiencias exitosas de lucha y una mayor comprensión de cuáles eran los puntos débiles del capitalismo del momento. La oposición a la guerra del Vietnam, la Revolución cubana, el Mayo del 68 o la Primavera de Praga, entre otros, eran acontecimientos que nutrían el imaginario de los militantes y que configuraron un clima cultural y de rebeldía que, al igual que un campo magnético, tendió a orientar en una dirección determinada las manifestaciones que aparecían en puntos distintos del planeta. Es decir, este substrato común internacional en formación potenciaría los anhelos de una nueva generación hacia referentes y lugares comunes, tanto ideológicos como de praxis movilizadora. Se creaba así un campo de atracción que animaba a determinadas adscripciones e implicaciones políticas en las personas que tenían unas experiencias, inquietudes o pulsiones vitales que las llevaban a sintonizar con él. De esta forma, las protestas internacionales o en el propio país tendrían una capacidad evocativa para muchas personas. Asimismo, eran acontecimientos que abrían una grieta en la normalidad y que permitían identificarse con unos movimientos internacionales que apuntaban alternativas al imperialismo y al capitalismo.

7 Para todo este ciclo de contestación, véase Teodori (1978), Harman (1998) y Horn (2007). 


\section{Cultura política e imaginario de los COC-OIC}

La cultura política es un elemento clave para entender los fundamentos de la militancia de alto compromiso, ya que se trata de una poderosa malla que dota de sentido la actividad del militante. Para afrontar esta cuestión vale la pena empezar resumiendo brevemente la historia de la OIC.

La Organización de Izquierda Comunista, si bien existió con este nombre entre 1974 y $1979,{ }^{8}$ partía de una organización previa llamada Círculos Obreros Comunistas (COC), surgida en 1971 a partir del movimiento obrero de base radical de Barcelona y del Vallés y de un grupo de militantes procedentes del Front Obrer de Catalunya (FOC) (Sans 2013). Dentro del campo de la izquierda revolucionaria, los COC y la OIC se situaban en el espacio de la izquierda comunista, y el utillaje ideológico que utilizaron para desarrollar su proyecto político fue una mezcla particular de consejismo, leninismo y marxismo heterodoxo. La OIC fue una organización hasta cierto punto original, surgida al calor de la lucha obrera, distante de las principales corrientes ideológicas de la izquierda radical del momento, como el maoísmo, el marxismo-leninismo y el trotskismo. Su forma de intervenir en el movimiento obrero fue a través de las Plataformas de Comisiones Obreras o Comisiones Obreras Anticapitalistas entre la diversidad de nombres que usaron-, un poco más amplias que la organización, pero lideradas por sus militantes. La organización tuvo un notable crecimiento, se fue extendiendo por distintas zonas del estado y fue capaz de liderar algunos conflictos obreros de alta intensidad en el año 1976, por ejemplo, en Vitoria, Sabadell o Córdoba, entre otros. Sin embargo, las posibilidades de un cambio radical en la sociedad que la organización preveía próximas fueron frustradas por la forma que tomó la Transición: el cambio real que se producía fue una democracia parlamentaria, no el socialismo, y con ello se frustraban los sueños de miles de militantes - de la OIC y de otras organizaciones - que habían dedicado gran parte de su juventud a la lucha social y política. La OIC sufrió espe-

8 Para ser más precisos, el nombre inicial en 1974 fue Organización de Izquierda Comunista de España (OICE), que cambió a OIC (sin la "E" de "España") a principios de 1977. Para una mayor claridad utilizamos únicamente este segundo nombre en el presente artículo. 
cialmente el cambio de momento y la organización desapareció como tal en 1979, si bien una parte de ella se integró en el Movimiento Comunista, de raíz maoísta.

Habiendo hecho este repaso sobre la trayectoria de la organización, podemos entrar en la cuestión de su cultura política, en la que convergieron tres tradiciones políticas. En primer lugar, a un nivel más ideológico, encontramos su definición como marxista, revolucionaria y comunista. Pero los referentes ideológicos del comunismo de la OIC eran muy amplios - aunque siempre ubicados dentro del campo del marxismo revolucionario-, lo que confería personalidad propia a su proyecto. Aparte del tronco de Marx, Engels y Lenin, común con los partidos comunistas (si bien poniéndoles distinto acento en la interpretación), había referencias a autores disidentes respecto a la tradición comunista soviética como Luxemburg, Trotsky, Nin y el consejista Pannekoek. Además, se sumaban a ellos Antonio Gramsci, György Lukács, Mao-Tse-Tung y el Che Guevara. Y, dentro de las expresiones políticas internacionales del momento, había una influencia de la izquierda italiana, con una atención a Il Manifesto, autores como Luigio Magri y Rossana Rossanda, los autónomos, los situacionistas y la experiencia revolucionaria portuguesa. ${ }^{9}$

Así pues, los COC-OIC combinaban el imaginario comunista con una visión amplia y sincrética de los referentes ideológicos. En términos de identidad política todo ello se acaba expresando en tres denominaciones que les permitían definir su espacio en el espectro político. La primera es la de "izquierda comunista", que les servía para definirse como comunistas, pero al mismo tiempo marcar diferencias con las políticas del Partido Comunista y de las organizaciones maoístas. La segunda es la de "consejismo", que articulaba su visión de la lucha obrera, y que recogían de trabajos de Gramsci y, de forma más distintiva, de Pannekoek. La tercera es la de "anticapitalismo", que ya provenía de los tiempos del FOC y sería utilizado en propuestas políticas como el Bloque Histórico Anticapitalista y Revolucionario ${ }^{10}$ o en el nombre de las Plataformas Anticapi-

9 Entrevista a Dolors Igual.

10 «El movimiento anticapitalista en la construcción del bloque histórico anticapitalista y revolucionario», Organización de Izquierda Comunista de España, julio de 1975, CEDOC, FO 45/o14. 
talistas y las Comisiones Obreras Anticapitalistas. Este término permitía, por un lado, remarcar el carácter de oposición al conjunto del sistema, y así distanciarse del reformismo; y por el otro, incidir en la dualidad entre capitalistas y trabajadores, y así subrayar el carácter de clase. De esta forma se juntaba la dimensión obrera y revolucionaria en un solo concepto y se podía hablar, con relación al franquismo, de la «dictadura terrorista de los capitalistas» y de sus «crímenes capitalistas». ${ }^{11}$ Además, la palabra "anticapitalista" era poco usada dentro de la izquierda revolucionaria del momento. Como explica José María Martín, el anticapitalismo «era nuestra seña de identidad creo yo en aquel momento». ${ }^{12}$

Siguiendo con las tradiciones políticas, en segundo lugar la OIC recogió el substrato de la cultura obrera de base. No se trataba solamente de un obrerismo ideológico, de considerar que la clase obrera era el agente fundamental de la revolución, algo compartido con el resto de la izquierda revolucionaria. Había también un obrerismo en cuanto a origen y praxis, ya que se recogía un bagaje del radicalismo obrero del momento y también de la militancia obrera mencionada. Los COC-OIC, con sus orígenes en los sectores obreros del FOC y en ¿Qué Hacer?-CFC, se conformaron principalmente a partir de activistas obreros que llevaban a sus espaldas un bagaje de lucha asamblearia en las fábricas. Así, desde las Plataformas se consideraba la asamblea obrera «el único instrumento y organismo soberano y dirigente de nuestra lucha». ${ }^{13}$ De esta forma, se asumía tanto la idea de la autonomía de clase, desarrollada por ¿Qué hacer?-CFC y referentes como Pannekoek, como la idea de organización de vanguardia procedente del leninismo.

En tercer lugar, finalmente, tuvo influencia en los COC-OIC que el grueso de su primera militancia procediera del catolicismo obrero, concretamente de la Juventud Obrera Católica (JOC). Este hecho característico reforzaba la cultura obrera de base de la organización y conllevaba

11 «A toda la clase obrera y al pueblo trabajador de España», Revolución 2 (oct. 1975), Arxiu del Crai - Biblioteca del Pavelló de la República (ACRAIBPR).

12 Entrevista realizada por Joel Sans a José María Martín Ruiz (responsable de COC y OIC en Santa Coloma y miembro del Comité Regional de Cataluña), Premià de Mar (Barcelona), 17 de marzo de 2017.

13 «Manifiesto de las Comisiones Obreras de Empresa y Plataformas Anticapitalistas de España», diciembre de 1973, CEDOC, FO 19/014. 
que se asumiera una moral de implicación y de entrega hacia la problemática social. Había en ello un cierto "apostolado social", que se expresaba en una concepción de extensión de consciencia y de movilización, más que de organización, y en las proletarizaciones, tanto de militantes de origen no obrero que iban a las fábricas, como de los que iban a vivir en los barrios obreros y a involucrarse en el movimiento vecinal. ${ }^{14}$ Acerca de la militancia que hacían los militantes que se proletarizaron en el barrio obrero de Singuerlín (Santa Coloma), Gabriela Serra cuenta que hubo una cierta sorpresa inicial por parte de los vecinos, aunque luego hubo muy buena relación:

crec que a vegades també ens confonien amb monges també, perquè hi havia les monges i l'esquerra radical, per dir-ho d'alguna manera, no? Teníem una colla de [monges] javerianas allà, que eren revolucionàries totals. Però això també et donava una certa... la gent et mostrava molt de carinyo. ${ }^{15}$

Para resumir, podríamos decir, pues, que en la cultura política de los COC-OIC convergieron principalmente tres tradiciones distintas: la cultura comunista y la cultura revolucionaria (con referentes heterogéneos), la cultura obrera de base y el compromiso social procedente del cristianismo obrero. Todo ello se plasmaba en varias ideas y valores guía: revolución, anticapitalismo, oposición a métodos de lucha pacifistas, obrerismo, solidaridad de clase, lucha radical y asamblearia, consejos obreros, poder obrero y partido revolucionario.

Además de los elementos de tradición política mencionados, también había otros aspectos que actuaban en la cultura política como un incentivador para la implicación militante. Uno de ellos era la actitud de fidelidad hacia la organización, con sus distintas caras: hacia un marco orgánico colectivo, hacia unas ideas y también hacia unas personas de referencia en el liderazgo. También había ciertos elementos simbólicos y mitos que funcionaban como aglutinador. Esto es un rasgo común en los distintos

14 Como sucedió en las experiencias de Dolors Igual o de Gabriela Serra. Entrevista realizada por Joel Sans a Dolors Igual y entrevista a Gabriela Serra (activista vecinal de Santa Coloma y Secretaria General de la OIC en Cataluña a partir de 1978), Barcelona, 25 de febrero de 2017.

15 Entrevista a Gabriela Serra. 
partidos, aunque en la izquierda revolucionaria los elementos de refuerzo de la adhesión tenían unos relieves distintos a los del PCE. En este último encontramos un partido con una historia de referencia, con sus raíces en la Segunda República y la Guerra Civil, con líderes con una larga trayectoria, como Santiago Carrillo y la Pasionaria, que actuaban como mitos vivientes. Además, había la referencia de otro mito, como era el llamado socialismo real de la URSS. ${ }^{16}$ Por otro lado, el partido tenía una dimensión pública y capacidad organizativa que le daba poder de atracción por ser la primera fuerza del antifranquismo. Por ello, en el compromiso militante hacia este partido, «en muchas ocasiones lo ideológico quedó en segundo término, pues no fueron pocos los que se enrolaron en las filas comunistas simplemente porque el partido disponía de una organización atractiva, potente, solidaria y capaz de desafiar al régimen» (Martín, González \& Ortiz 2009, 26).

En las organizaciones de la izquierda revolucionaria existían también mitos, pero estaban menos conectados al propio partido, que tenía una trayectoria histórica muy corta desde finales de los años sesenta o principios de los setenta. Eran, por lo tanto, mitos de tinte más ideológico: determinados autores marxistas, figuras revolucionarias o hechos históricos de cambios políticos radicales - como la Revolución rusa-o determinados conceptos. En este sentido, y de forma compartida con el PCE, tenía peso el mito de la huelga general, como momento en el cual se podían abrir las puertas al cambio que todo lo transformara (Domènech 2009, 124). Como alternativa al mito de la URSS actuaba en los partidos maoístas la afinidad a China. En el trotskismo, a otro nivel, la existencia de una Internacional de referencia también proporcionaba un elemento identificativo de refuerzo. Pero en el caso de la OIC no había una adscripción a ningún país o marco internacional que pudiera actuar en forma de mito, más allá de contactos y simpatías con ciertas organizaciones.

Las ideas fuerza que seguramente tuvieron más peso en la OIC fueron la de los consejos obreros y la de la revolución, con mucha conexión con las experiencias de los años diez y veinte, como los soviets y la Revolución rusa y la Revolución española de 1936. A ello se puede sumar una 
cierta mitificación de la clase obrera como agente revolucionario. En cualquier caso, la OIC tenía la dificultad de que no se insería en una tradición política fuerte, desarrollada en el tiempo, pues los principales referentes del comunismo de izquierda de la organización eran diversificados y matizados entre sí, con pensadores que iban del consejismo al leninismo. El peso diferencial y distintivo del consejismo en el proyecto de la OIC hizo que con el cambio de perspectivas de la lucha obrera en 1976-1977 se socavara una de las principales piedras angulares del marco ideológico, sin que los otros asideros políticos fueran suficientes para proporcionar una orientación fuerte.

Para terminar de señalar los vectores que nutrían la cultura política de la OIC, podemos añadir dos cuestiones más. La primera es el tema de la moral comunista, algo que a veces es poco teorizado conscientemente pero que tiene una indudable importancia a la hora de sustentar el compromiso. En los COC-OIC había una visión moral de lo que significaba ser comunista y el tipo de comportamiento y actitud que se esperaba de los militantes, como se ve en los documentos de la organización. Hay una frase de la OIC que denota la idea de sacrificio y del militante como combatiente: «Comunismo o muerte: venceremos». ${ }^{17}$ Esta formulación dramática, de inspiración castrista, situaba una clara disyuntiva en torno a las dos posibilidades existentes - socialismo o muerte- y al sacrificio total para conseguir una de ellas. La idea de «venceremos» remite al optimismo de que, en última instancia, se va en la dirección positiva de la historia.

Hay un tono de cierto dramatismo y agresividad en esta y otras formulaciones. Así, se habla de que la situación de ruptura política entre teoría y práctica que se está produciendo «es un gran crimen» que si se mantiene fortalece al sistema capitalista y garantiza al proletariado ir de derrota en derrota. O en una línea similar: «la existencia de núcleos y organizaciones no unificadas, cuando se dan las bases de la unidad teórica y política exigibles, sería un acto criminal y claramente dirigido contra el proletariado». Se realiza un juicio implacable de lo que se interpretan como

17 Aparece, entre otros textos, en: «Declaración de fusión entre Núcleos Obreros Comunistas de Euzkadi y Círculos Obreros Comunistas», Izquierda Comunista, edición especial, octubre de 1974, DDD-UAB. 
errores políticos: la situación de «reinos de taifas» en la izquierda no es sino «fruto de un espíritu claramente contrarrevolucionario». ${ }^{18}$

Además, hay una visión de que el desarrollo de la propia organización conlleva asumir mayores responsabilidades. Así, la fundación de la OIC «nos compromete a responsabilidades superiores ante las masas y en la lucha de clases y es tarea de todos el cumplir dichas exigencias en esta hora histórica de la Revolución Socialista». ${ }^{19}$ La idea de la responsabilidad, del deber, del sacrificio hacia la causa y hacia lo que toca, forma parte del imaginario y es central para el compromiso militante.

La segunda cuestión es la visión militarizada de la política y el militante como combatiente. La propia política contiene, por el carácter competitivo que implica la lucha por espacios de poder, un cierto carácter militar en el vocabulario. En el caso de la izquierda marxista son habituales palabras como estrategia, táctica, ofensiva, enemigos, aliados, guerra de posiciones, guerra de movimientos, lucha de clases, vanguardia, bando, cuadros o filas. La política está concebida como una batalla, como una guerra entre distintas fuerzas políticas y sociales, y los resultados se conciben en términos de victorias o derrotas. Esta visión militarizada estaba muy presente en el imaginario de la izquierda radical, pero también en el PCE-PSUC. Como explica Giaime Pala acerca del Partido Comunista, se fomentaba la imagen del militante como «combatiente disciplinado y aguerrido al servicio del pueblo oprimido» (Pala 2013). O, como explica Gregorio Morán, con su pluma un poco simplificadora pero gráfica: «En clandestinidad existía una ingenua pero férrea conciencia de ser soldados de la revolución, no políticos en ejercicio» (Morán 1986, 508-509).

Cabe decir que este espíritu de combatiente también se movía dentro de distintos grados. En este sentido, en la OIC había un grado significativo de autonomía personal y el encuadre disciplinario era menor en relación con el PCE y las principales organizaciones maoístas. Aún así, también en la organización consejista había mucha influencia de la visión del revolucionario como combatiente. Además del contexto de la clandestinidad y de la represión, el auge de luchas contra la dictadura reforzaba 
la idea de embate. Ello, asimismo, estaba vinculado a la propia idea de la violencia revolucionaria como algo necesario para el cambio de sistema. Como ejemplos de este uso del vocabulario, el periódico Revolución era «el arma de combate diario». O en un documento de 1976 se decía:

Nuestro lema debe ser depurar los errores, avanzando con las masas en la defensa de un programa de lucha por la Revolución Socialista en su quehacer diario. Sólo esto [...] hará posible recobrar la iniciativa política en la lucha de masas; condición imprescindible para conseguir que el proletariado y el Bloque Histórico Anticapitalista y Revolucionario tomen la iniciativa [...], a través de desarrollar una amplia y clara ofensiva, que sitúe cuáles son los objetivos a conquistar y cuáles las batallas a librar. ${ }^{20}$

La idea de la política como combate es muy pertinente para ver los mecanismos de refuerzo del compromiso militante, entre un "nosotros" inclusivo - los obreros y revolucionarios - frente a un "ellos" - los capitalistas y los que les dan apoyo- - Esta concepción, sumada a los mecanismos de identificación con el partido, al convencimiento político de la línea correcta con relación a otros grupos, y a la falta de recorrido y de madurez de las organizaciones revolucionarias, muy jóvenes, fomentaba también una actitud de sectarismo hacia las otras organizaciones. De hecho, la doctrina política de una organización puede crear — dependiendo de cómo esté construida - una estructura muy sólida en forma de pensar, que sea el patrón desde el que se escuchan las otras corrientes y la vara de medir y de interpretar otras opiniones. La OIC contó con este tipo de visión ideológica fuerte, de adscribirse un papel muy fundamental y de cierta superioridad política. Así escribían: «Los comunistas representan la teoría más avanzada de cada momento histórico», y tienen una «larga tradición de lucha [...] por enderezar el sendero de la historia bajo unas coordenadas científicas». ${ }^{21}$ Hay una otorgación a uno mismo (un «uno mismo» colectivo, pero también traspasado hacia el militante indi-

20 Rafael Márquez, Tesis Generales Básicas. Declaración de la segunda sesión del Primer Congreso, Organización de Izquierda Comunista de España, agosto de 1976, p. 16.

21 «Declaración de fusión entre Núcleos Obreros Comunistas...». 
vidual) de tener la razón, algo que debilita la empatía hacia los otros y las posibilidades de establecer diálogo y acuerdos con otras organizaciones. Ello contribuía al sectarismo y a mirar hacia dentro, y dificultaba poder ver las cosas de una forma distinta a las del prisma del propio sistema político e ideológico. Como explica el militante Emilio Espín:

la polémica con los demás movimientos que podía haber cuando se coincidía en determinadas acciones, movilizaciones o debates. [...] la izquierda siempre se ha caracterizado por estar muy atomizada, muy atomizada, y con un enfoque ideológico muy... muy sólido o sectario, digamos, que preparaba a la militancia de cada uno de los sectores también para enfrentar los debates con el resto de corrientes y pensamientos políticos, no? ${ }^{22}$

Desde el autoconvencimiento fuerte era fácil percibir inconscientemente las ideas distintas como una agresión hacia las propias ideas o hacia la causa. En el momento de la Transición el responsable de las JIC, Jorge Núñez, hacía una fuerte autocrítica del sectarismo presente en la organización juvenil:

Una extraña fe casi religiosa en nuestras filas con respecto a la política de las JIC, un sentimiento cercano al dogma de ser la verdadera vanguardia sin reconocer los errores [...] nos ha llevado irremediablemente a creer que las posiciones del resto de vanguardias merecía nuestra indignación y el insulto más hiriente que fuera capaz de arrojar a la cara del resto de militantes de otras organizaciones la vergüenza de pertenecer a ellas. ${ }^{23}$

¿Hasta qué punto las cuestiones de cultura política mencionadas fueron importantes para la entrada en la militancia? Es verdad que para las personas que se unían a una determinada organización de la izquierda los motivos para escoger una de ellas no siempre eran políticos; pesaba el entorno de amistades y la influencia que tuvieran las distintas organi-

22 Entrevista realizada por Joel Sans a Emilio Espín Amprimo (militante de OIC y líder obrero en la Unidad Hermética), Sabadell, 27 de abril y 11 de mayo de 2015.

23 Contra el sectarismo, [1977 o 1978], Archivo Personal de Jorge Núñez (APJN). 
zaciones en el lugar. Sin embargo, en el caso de las organizaciones de la izquierda revolucionaria, y especialmente en las no tan grandes, como la OIC, el tipo de cultura política y la afinidad ideológica eran factores más decisivos. Claro está que el hecho de que la OIC tuviera un arraigo importante y capacidad de liderazgo en determinados barrios, poblaciones, sectores laborales o fábricas fue un estímulo para la involucración de personas que vieron en el activismo de miembros de la organización un punto de referencia, más allá a veces de factores ideológicos. Pero aún así, el componente ideológico antiestalinista y consejista (en favor de la democracia obrera) era muy marcado y aparece en las entrevistas como un factor que influyó en bastantes casos. En el apoyo a la propuesta consejista de la OIC confluyeron la búsqueda de una alternativa al modelo de partido jerárquico y una fuerte identificación con el radicalismo obrero asociado al auge huelguístico. Ello explica la entrada en la OIC de círculos de personas aislados en zonas donde no existía la organización, lo que permitió su extensión territorial a Euskadi y Andalucía, por ejemplo. Un caso destacado es el de José María Santamarta, de Miranda de Ebro, que entró individualmente en la organización a partir del contacto con un militante de Barcelona que le pasó materiales. ${ }^{24}$ En ello influyó principalmente el componente ideológico y también el peso de la OIC (o anteriormente los $\mathrm{COC}$ ) en las luchas obreras del Vallés a través de las Plataformas Anticapitalistas, su espacio de intervención en el movimiento obrero.

Tras haber reseguido el marco de la cultura política de la OIC — su tradición política, identidad, mitos, ideas fuerza, moral y actitud de la política como batalla-, podemos pasar a ver algo estrechamente vinculado a ella: la concepción de la militancia.

\section{El modelo de militancia de la OIC}

La visión sobre la militancia de los COC-OIC recogió y amplió aspectos presentes en el radicalismo obrero y los Círculos de Formación de Cuadros (CFC) de Barcelona, de los que se provenía. Aunque los CFC no fue-

24 Entrevista realizada por Joel Sans a José María Santamarta (activista obrero de la OIC en Miranda de Ebro, Gipuzkoa y Araba), Miranda de Ebro, 29 de octubre de 2014. 
ran una organización política estructurada (Pasajes 2008), no por ello la vinculación militante que se planteaba era reducida. Como decía el sector en su seno que formaría posteriormente los COC y OIC: «teniendo en cuenta nuestros vicios anárquicos y que trabajamos para la organización de clase futura, se nos debe exigir y controlar la militancia a un nivel similar al de los grupos políticos».5 Aún así, y manteniendo esta visión de compromiso intenso, el modelo de militancia fue transformándose en el tiempo, por un lado por el cambio de contexto — con la ampliación de la lucha social y antifranquista-y, por otro, debido a la propia evolución y maduración de la organización, que en aquellos momentos estaba en plena definición de proyecto.

Dos circulares de los Círculos Obreros Comunistas, así como su documento de «Definiciones provisionales», dan una buena indicación del modelo de militancia que se planteaba a principios de los setenta y de lo que se esperaba de los militantes. El punto fundamental de la concepción de la militancia en los primeros años era la consideración de que la dedicación a la causa, el servicio a la revolución era el eje central de la vida de cada militante, y el resto de los aspectos pasaban a un segundo nivel, si no a una situación de subordinación. Así se planteaba que «la Revolución debe ser el aspecto fundamental y total que preside nuestra vida» y que el militante «debe poner toda la atención, todo su entusiasmo, su preocupación, su capacidad, su vida al servicio de la Revolución y de todo aquello que ésta lleve aparejada». ${ }^{26}$ En consecuencia, se concebía que el tiempo de dedicación debía ser «todo el que dispongamos» y se identificaba que la entrega debía estar por delante del resto de intereses de la persona: «no es revolucionario ver las posibilidades de crecimiento de la lucha y dejarlas pasar por comodismo o falso respeto a las "necesidades personales de equilibrio”». Aunque se añadía también que ello no debía sobrepasar ciertos límites, pues el militante «debe ordenarse el tiempo para poder realizar las actividades sin que esto signifique atosigamiento o desequilibrio psíquico», si bien parece que esto se inscribía más en una lógica de evitar el desgaste del militante, que no de una concepción en la que se tuviera

25 Criterios Políticos y de Militancia, Círculo “Pájaros" de CFC, s. f., IISG, Fondo JMGP, Carpeta 1735. 26 Definiciones provisionales de Círculos Obreros Comunistas, julio 1972, CEDOC, FO 11/017, p. 39. 
en cuenta un espacio personal fuera de la política. ${ }^{27}$ De forma similar, en otro documento se decía que lo que se discutía no era que «los militantes tengan que ir desquiciados» —en una expresión indicativa de lo que podía suceder - sino «los mecanismos y orden de prioridades que la gente se autoestablece». ${ }^{28}$ La asunción de este compromiso tenía efectos sobre la práctica, ya que el sitio donde se vivía y el lugar de trabajo tenían importancia política y debían «ser obra de un análisis y decisión colectivos» y asumir colectivamente las necesidades económicas que eso conllevara. ${ }^{29}$

Se planteaba, en la circular de 1972, que los comunistas debían ser los militantes «con más nivel de militancia», para que su propio ejemplo sirviera de propaganda y se contribuyera a elevar el nivel de lucha..$^{30}$ Todo ello estaba muy vinculado a una visión política de énfasis en el papel del factor subjetivo, del papel de los comunistas y de la voluntad organizada en la historia. El grado de compromiso que se reclamaba lleva a criticar a aquellos que anteponían lo personal: «Nos referimos a esos militantes para los cuales pesan más las relaciones de tipo familiar que la necesidad de crear una gran humanidad donde exista una posibilidad de vida libre y comunista para todas las familias del mundo». ${ }^{11}$ Por lo tanto, se planteaba expandir la visión más allá de las estrechas fronteras de la vida individual y de la familia de cada uno, ver la dimensión global de «los explotados de todo el mundo». Pero se hacía con una lógica de sacrificio de lo personal hacia la causa de la revolución y del comunismo, que debía estar en el primer plano.

El siguiente párrafo es muy ilustrativo de esta visión estricta sobre la militancia de los COC, pero en buena medida también de los planteamientos de entrega incondicional a principios de los años setenta y de la concepción moral presente de forma más amplia en la cultura política de la izquierda revolucionaria:

27 Ibídem, 39-41.

28 «[Militancia y prospección]. Circular $\mathrm{n}^{\circ}{ }^{1}$. Sobre la militancia de COC», septiembre de 1972; Hernández (1976, 87-96), APJN.

29 Definiciones provisionales de Círculos Obreros Comunistas..., 40.

30 «[Militancia y prospección]. Círcular $n^{\circ} 1 \ldots », 87-96$.

31 Ibídem, 88. 
Un comunista debe ser un hombre incondicionalmente dispuesto a realizar el tipo de trabajo a la hora que sea y cuando sea, debe ser el hombre de más nivel de militancia, debe ser el más disciplinado y riguroso en el funcionamiento, debe de postergar sus intereses y problemas personales a las exigencias de la práctica y de la lucha política, debe tener sus cinco sentidos puestos en el avance de la revolución, debe ser exigente y rígido en cuanto a su comportamiento moral, debe guardar vigilancia y fidelidad absoluta con los principios de la lucha por el comunismo (como una necesidad que es incuestionable). ${ }^{32}$

Como vemos, se demanda una entrega total a la causa comunista, no solamente en disciplina militante, sino también en convencimiento y en comportamiento moral.

Sin embargo, cabe decir que el modelo de dedicación militante total no deriva simplemente del marco ideológico de los COC; también estaba estrechamente vinculado a una realidad de clandestinidad, de ascenso de luchas, y del análisis que se hacía de la situación política y de lo que había en juego. En este sentido, la organización consejista consideraba que el carácter del momento conllevaba que la balanza del cambio radical se pudiera inclinar hacia el fascismo o hacia la revolución socialista, en función de la actuación de los revolucionarios. ${ }^{33}$ Más allá de los detalles de este análisis, no se puede dejar de tener en cuenta que refleja cómo el ascenso de combatividad de la lucha obrera y la respuesta represiva que ejercía el franquismo eran un gran estímulo para redoblar el compromiso militante y evitar un retroceso de los avances que se habían producido dentro del movimiento obrero.

En la segunda circular sobre militancia de los COC, de febrero de $1974,{ }^{34}$ se mantenía a grandes rasgos la misma aproximación sobre la militancia, pero se desarrollaban otros aspectos. No se ponía el acento de la misma forma en la entrega de la causa por encima de lo personal y de la importancia de la cuestión de subir la implicación, sino que el enfoque era más cualitativo, centrado en afrontar la compleja unión entre la teoría y la

32 Ibídem, 93-94.

33 Ibídem, 95.

34 «Circular $\mathrm{n}^{0}$ 2. Sobre la militancia. COC», Comité Provincial de Barcelona de los COC, febrero de 1974. Véase Hernández (1976, 97-127). 
práctica, y en desarrollar la formación y las capacidades que necesitaban los militantes. Y en septiembre de 1975, ya constituida la OIC, tenemos un extenso texto de 79 páginas de su líder, Dídac Fàbregas: El militante y la construcción del Partido Comunista (Hernández 1976, 7-86). De los muchos aspectos vinculados a la cuestión de la militancia, lo más original del documento es lo que se refiere a la moral. Se recoge de Lenin que sí existe una moral comunista, que «está subordinada por completo a los intereses de la lucha de clases del proletariado». Las características de esta moral pivotan sobre todo en su contraposición a la moral burguesa y su vínculo a la lucha por la revolución y el comunismo. Además, el dirigente de la OIC concebía la militancia como pieza dentro del camino hacia el comunismo, en el cual incluso rechazaba el presente, que se veía como un obstáculo que superar:

El futuro libre sólo se conquista en lucha abierta contra el presente y por lo tanto la dura militancia de la lucha por el comunismo es el precio insoslayable de la coherencia y del tesón real en la conquista del fin propuesto; quien quiere el fin ha de querer los medios. (Hernández 1976, 74-76)

Este tipo de formulación no era solo propia de los COC-OIC, sino que es de hecho algo común en el seno de las ideologías de las organizaciones de oposición de carácter minoritario. Como analiza Andrade, en este tipo de organizaciones hay una visión «crítico-desmitificadora» hacia las concepciones políticas dominantes del presente y una gran proyección hacia el futuro:

Las ideologías alternativas inspiran y legitiman una acción orientada hacia la transformación y el cambio y prima en ellas la dimensión utópica en un sentido blochiano, en el sentido de cifrar en el futuro las posibilidades de solución de un presente con el que se muestran inconformes. (Andrade 2012b, 38)

En este camino la OIC asume que la práctica militante tiene un contenido de dureza, pero que ello es inevitable si realmente se quiere el fin del capitalismo. Puede comportar mucha dedicación, pero es el precio de la coherencia y de la defensa de los ideales. Seguramente este es el elemen- 
to clave de moralidad que permite estructurar el compromiso y todas las atribuciones que conlleva. Se anuncian diversos aspectos de la moral comunista: la disciplina, asumida libremente; la constancia; el análisis riguroso y científico del momento presente, en el que se propone que la «fe en la revolución» sea algo que sale de un conocimiento profundo y no de ilusiones subjetivas; una actitud por parte del militante de crítica y autocrítica científica; la claridad y la honestidad, y la solidaridad de clase (Hernández 1976, 74-76).

Para poner un ejemplo más práctico del compromiso que se demandaba a los militantes, a finales de 1976, junto a la perspectiva de la masificación del partido y de incrementar la distribución de propaganda, se pedía a la militancia que asumiera en términos exigentes un nivel importante de ventas del periódico de la organización:

El militante que, trabajando en una fábrica de más de 100 trabajadores, no sea capaz de vender 20 Revoluciones es un pésimo militante; el militante que, estando trabajando en un barrio, no sea capaz de vender 30 Revoluciones en la Asociación de Vecinos es un pésimo militante, y tal cuestión refleja una incorrecta relación con las masas, representa un alejamiento de la correcta relación Partido/masas. ${ }^{35}$

La OIC planteaba incluso en los estatutos de 1977 —que eran una apertura respecto al modelo de militancia de la clandestinidad - una interpenetración importante entre la vida de la persona y la política: «Entendemos por militante comunista aquel que establece una fecunda y revolucionaria fusión entre la vida política y la vida personal o privada, entendiendo que la lucha por el comunismo es algo totalizador en la vida de cada hombre o mujer.» ${ }^{36}$

Todo ello refleja una concepción de entrega plena a la causa, en que la persona asume la responsabilidad como vanguardia para cambiar la historia y subordina el resto de los aspectos de su vida. Pero más allá, hay

35 "Circular de la OICE. Acerca de la propaganda», Secretariado General de la Organización de Izquierda Comunista, septiembre de 1976, Archivo Histórico de CCOO de Andalucía (AHCCOOA), p. 5-6.

36 «Estatutos de la OIC», Organización de Izquierda Comunista, [1977], Archivo Personal de Andy Durgan, cedido a Joel Sans. 
una visión en que la implicación política totaliza a las personas, con una concepción moral que busca un comportamiento y unas actitudes coherentes con el compromiso y las ideas.

\section{La relación entre política y persona}

Encontramos un interesante documento crítico del seno de la organización, de agosto de 1977, en el que se explica gráficamente el tipo de militancia que había sido habitual durante la clandestinidad:

Con la creencia de la inmediatez de la revolución, de las posibilidades de una salida revolucionaria a la muerte del dictador, la militancia llegó a extremos, a veces inusitados, de actividad, de "militantismo", de sacrificio, además en un marco represivo y clandestino especialmente duro. Eran las épocas no lejanas, de reuniones hasta altas horas de la noche, de dormir poco, de ir a repartir propaganda a las 5 de la mañana, de un activismo incesante, y a veces ineficaz, en que a un militante el partido le podía cambiar de frente o de localidad "porque la lucha de clases así lo exigía”.37

Los testimonios orales de antiguos miembros de la OIC nos permiten ilustrar de forma más directa cómo se vivió el modelo de militancia. La implicación no solamente era muy esforzada, sino que también tenía una moral marcada sobre lo que estaba bien considerado como práctica por parte de los militantes, y con la marginación de ciertas actitudes que se planteaban en la esfera personal:

En un contexto así, el surgimiento de cualquier forma de problema privado era considerado como una debilidad pequeñoburguesa; un bajón de militancia como una debilidad política o unas prácticas militantes alejadas de este modelo eran signo de "liberalismo pequeñoburgués". ${ }^{8}$

37 «Crisis de militancia o crisis de partido? Elementos para una alternativa en el momento actual, s.a.», agosto de 1977, caja 1366 (materiales de la OIC), AHCCOOA.

38 Ibídem. 
Acerca del nivel de entrega, José María Martín comenta:

A ver, la OIC... la militancia he de decir que era una militancia muy entregada y con una disponibilidad al máximo, esto hace que, por ejemplo, nosotros adjudiquemos un barrio donde has de ir a vivir con tu pareja. Algún compañero: «no, tú no puedes vivir aquí, tienes que ir a vivir a Las Oliveras», recuerdo perfectamente el caso, no? ${ }^{39}$

Este tipo de implicación conllevaba la dificultad de combinar el trabajo en la fábrica y toda la actividad política fuera de ella:

És que era fort, era tot el dia en funció d'això, sorties de treballar, dinaves i de seguida hi havia una cosa o altra, fins a les 11 de la nit i amb el perill que també comportava estar rondant per les nits a [...]. Era un tema... és que la teva vida estava en funció d'això, pràcticament no tenies vida privada..$^{40}$

Jorge Núñez, que fue liberado de organización juvenil, estuvo implicado de una forma enorme entre los 13 y los 21 años. Ello supuso no vivir como tal la adolescencia y, por las responsabilidades que fue cogiendo, adoptar unas pautas de comportamiento de una persona más mayor: «yo con $16,17,18$ años me comportaba como un hombre adulto, yo recuerdo con 17-18 años viajando a un Comité Ejecutivo Central de la OIC». ${ }^{41}$ Como documento muy interesante se ha conservado la agenda de este militante. Reproducimos tres semanas de actividad, del mes de febrero de 1978, momento en que, a la edad de 20 años, tenía como responsabilidades ser liberado de las JIC y miembro de su Comité Ejecutivo Central, además de participar en el Comité Ejecutivo de la OIC, entre otras:

39 Entrevista a José María Martín Ruiz.

40 Entrevista realizada por Joel Sans por videoconferencia a Joana (militante de COC y OIC en el Vallés y el País Valencià), 27 de junio de 2016. Entrevista realizada bajo seudónimo.

41 Entrevista realizada por Joel Sans a Jorge Núñez (Secretario General de las Juventudes de Izquierda Comunista y del Comité Central de la OIC), Madrid, 24 y 26 de junio de 2016. Entrevista citada bajo seudónimo. 
Lunes 6 de febrero: Comité Ejecutivo de las JIC. | Martes 7: Finalizar informe del Consejo de la Juventud. | Miércoles 8: Comité Ejecutivo de la OIC. | Jueves 9: Comité Ejecutivo Central de las JIC. | Viernes 10: Comité de Estudiantes. | Sábado11 y Domingo 12: Comité Ejecutivo de las JIC.

Lunes 13: Comité Ejecutivo de Madrid de las JIC. | Martes 14: Reunión Extraordinaria del Consejo Federal de Partidos Juveniles. | Miércoles 15: Reunión del Comité Ejecutivo Central de las JIC. | Jueves 16: Reunión entre las JIC y las juventudes del MC y reunión del Comité de Enseñanza Media. |Viernes 17: Reunión del Comité Ejecutivo Central de las JIC y reunión con las Juventudes Revolucionarias del MC. | Sábado 18 y domingo 19: Reunión Comité Ejecutivo de la OIC.

Lunes 20: Comité Ejecutivo Central de las JIC. | Martes 21: Reunión con la Federación de Juventudes Revolucionarias y reunión con la Comisión Permanente para la Fusión OIC-MC. | Miércoles 22: Reunión por un tema del Consejo de la Juventud.|Jueves 23: Reunión en la sede de la OIC con los responsables de Enseñanzas Medias. | Viernes 24: Reunión Consejo de la Juventud y reunión del Consejo Ejecutivo de Madrid de la OIC. | Sábado 25 y Domingo 26: Conferencia de cuadros de la OIC. ${ }^{2}$

Como vemos, había una actividad constante, en múltiples comités, sin días de descanso y con reuniones y encuentros los fines de semana, que ocupaban todo el día.

Para entender la intensa relación entre la persona y la política que muestran los testimonios, cabe decir que esta no es sencilla, ni directa, sino que hay una construcción de la relación y una intermediación de una multiplicidad de elementos que la sustentan, desde los más sociales a los más psicológicos y personales: el contexto socioeconómico y político (tanto en la España franquista como en la dimensión internacional de auge de contestación mencionada anteriormente); el entorno de sociabilización, desde el que hay una transmisión de valores, actitudes e identidades, con la familia en primera instancia, y los sitios en los que se ha vivido, los lugares de estudio y de trabajo, en segunda; la propia experiencia y trayec-

42 Agenda personal de Jorge Núñez, de 1978, APJN, comentada por su propietario. 
toria de involucración y activismo, con un poso de vivencias y emociones; la pertenencia al colectivo u organización y la cultura política y modelo de militancia que esta plantea; un sistema de creencias, con la ideología como principal eje estructurador; la propia personalidad; los anhelos e inquietudes vitales de la persona y también los interrogantes existenciales sobre el papel de uno en el mundo.

De esta forma, el compromiso político puede ayudar a cubrir necesidades que tiene la persona de posicionarse y ocupar un sitio personal frente a un determinado contexto político y social. Le permite configurar una comprensión sobre el mundo y posicionarse respecto a él. La política puede ser la canalización específica de ciertas preguntas de sentido vital, una forma de socializarse en un determinado entorno o la reacción frente a una determinada situación social y política que se cualifica de injusta, lo cual ayuda a dar un sentido a la vida y a configurar la propia subjetividad. Esta capacidad de dar sentido que tiene la política se ha relacionado con la idea de que el proceso de secularización de las sociedades desde la revolución francesa haya dado nuevas formas de trascendencia, una metamorfosis de lo sagrado, que pasaría a englobar otros ámbitos que nutrirían el vacío dejado por el declive de la religión, con una sacralización de la política (Box 2006, 222). Una capacidad que se muestra en la militancia juvenil en Albacete, cuyo «objetivo político fue progresivamente impregnando e incluso apoderándose de facetas antes exclusivas de la cotidianidad» a partir de la relación de compañerismo, lazos de amistad y militancia. «Tanto, que la militancia se convirtió en una poderosa fuente de sentido vital al comportar, como nos relataba una militante comunista, "una situación en la que no había marcha atrás sin antes traicionar la propia identidad"». También, a partir de la experiencia e implicación en las redes de sociabilidad, «muchos jóvenes sintieron la política como un eje articulador de su existencia cotidiana hasta el punto de que para los más concienciados les era imposible deslindar lo político de lo personal ("militantes las veinticuatro horas del día")» (Martín, González \& Ortiz 2009, 29).

En la relación entre militancia política y vida, encontramos un indudable componente generacional. La juventud tuvo un peso decisivo en nutrir el antifranquismo y en dinamizar la movilización. Así, el 67\% de los 
procesados por el Tribunal de Orden Público eran menores de 31 años y el 77\% menores de 35 (Martín, González \& Ortiz 2009, 21). La mayoría del activismo estaba realizado por jóvenes, lo que indica la capacidad que tuvieron los segmentos más nuevos de la sociedad de influir a su conjunto y su protagonismo como impulsor del cambio político.

En la OIC el factor de juventud era muy claro. De la treintena de entrevistas realizadas a antiguos miembros de la organización, el grueso de personas nació entre mediados de los años cuarenta (algunas personas nacidas al inicio de los años cuarenta y la excepción de una persona nacida en el año 1937) y mediados de los años cincuenta (la más joven nació en 1957). Esto significa que la mayoría de las personas entrevistadas —en las que hay un perfil diverso, pero una proporción significativa de cuadros dirigentes - tenía en 1975 entre veinte y treinta años.

Este componente de edad muchas veces se manifestaba también como ruptura generacional con los padres. Los chicos y chicas jóvenes querían manifestar otra actitud hacia la política y las pautas sociales establecidas que sus progenitores. Aunque la familia fuera de tradición de izquierdas o republicana y se opusiera al régimen, el peso del miedo era muy importante. Así, como muestra el testimonio de Dolors Igual, militante de la OIC en el País Valenciano, aunque su padre tenía un claro posicionamiento antifranquista y se hablaba abiertamente de política en casa, el hecho de hacer actividad política o de militar era visto con ojos completamente distintos:

Però mon pare me va pillar uns panfletos i, bueno, se moria, eh?, li tremolava la mà, se volia morir, perquè tenia el pànic eixe que deia «es que a ti te pillarán, tu no sabes: te meterán en la cárcel, porque eres hijo de quien eres», i a mi clar, jo era... tenia 16 anys i a mi lo que me deia mon pare, que era un abuelo pa mi, me pareixia una bobada [...]. Era terror, era terror a la militància, i terror... sí, perquè se sentien marcats, clar, clar, molt marcats i entonces tenien la por de que si fèiem algo, eh... això, seria terrible.

En su evolución política Dolors Igual desarrolló el sentimiento de querer ir más allá políticamente que su padre, hacia posiciones revolucionarias: «Clar, jo no era d'estos d'això, de fills de franquista que ens fem anti- 
franquista i ja fem prou, sinó que nosaltres havia de ser alguna cosa més, antifranquista no era prou, perquè això ja ho era mon pare [...] o jo què sé, o ser demòcrata no era prou».43

En un contexto muy distinto, Lourdes Ponce, que más tarde sería militante de la OIC, explicaba cómo había vivido esta distancia generacional con su familia, con unos padres religiosos, monárquicos y conservadores:

[Los hermanos mayores] han sido siempre muy a las diez en casa, de tal, de cual, y de repente les sale la pequeña de la generación del 68. Pues claro, para mis padres fue un choque, un choque tremendo. Y, sin embargo, yo no lo he vivido mal. O sea, lo he vivido con broncas.

Hay pequeñas anécdotas que muestran cómo van cambiando actitudes y se van rompiendo los moldes establecidos de comportamiento a partir de gestos de rebeldía juvenil. Así Lourdes Ponce explica que su padre reconocería en una reunión familiar:

A mí me vais a decir lo que cambian los tiempos. Mis hijos hasta que no han hecho la mili no les he dejado fumar delante de mí. Y esta, mujer [Lourdes Ponce] y con dieciocho años, ni me pide permiso: tiene el valor de venir y decirme que le dé fuego. 44

El componente de la juventud aportaba, por otro lado, mucha capacidad de entrega y energía. Dolors Igual explica cómo se vivía una ilusión muy grande por lo que se estaba haciendo, con la idea de que se estaba construyendo un nuevo mundo que estaba a tocar con la mano:

Clar, unes coses..., jo a vegades ho pense! Però clar, és que teníem 19 anys, 20, i el món era... era tot, no sé, estava com tot per construir, no? Era una sensació eixa, clar. Eres jove, tens illusió, el franquisme te fa por, però clar, ja era al final.

43 Entrevista a Dolors Igual.

44 Entrevista realizada por Conchi Villar a Lourdes Ponce Noria (militante obrera de la OIC en Barcelona) entre 11 de enero y 10 de febrero de 2000, y transcrita por Raquel Oliver. Fundació Cipriano Garcia - Arxiu Històric de la CONC (AHCONC), fons d'Història Oral i Militància Sindical. Biografies Obreres (1939-1978). 
Bueno no, que passaven putades i hi havia gent que la torturaven. Això ja te dic, a mi me van posar la pistola dues vegades allí en el cap, eh?, quan anàvem a repartir a la Ford. Veus? Propaganda de l'OIC. La policia això de parar-te el cotxe i pum!, no? La pistola, eh? ${ }^{45}$

En su caso, la efervescencia de lo que se estaba viviendo y la curiosidad por lo que se estaba moviendo superaba el miedo y permitía superponerse a la persecución policial.

Enrique Pérez, dirigente de la OIC en Madrid, explica la gran capacidad de entrega militante a través del convencimiento que tenían ante la situación política y social del franquismo, pero también ayudado por el dinamismo de ser jóvenes:

Yo creo que la energía la sacas del convencimiento: esto hay que hacerlo y hay que hacerlo. Por eso no había horas, no? Era la cosa que tenías que hacer como persona y como tal, y como pueblo, esto hay que hacerlo. Y bueno, y eso, y que tenías veinte pocos años [ríe]. ${ }^{46}$

\section{Sacrificio y vida: la dualidad de la militancia}

El modelo de militancia que se plantea desde la OIC tiende, especialmente durante la clandestinidad y hasta 1977, cuando hay una cierta apertura, a supeditar a la persona a las necesidades políticas de la causa y de la organización, lo cual no está exento de tensiones personales. Como hemos visto, hay una moral militante voluntarista y de sacrificio, muy vinculada al marco ideológico de la organización. El militante Toni Pons lo ilustra de la siguiente forma:

Los componentes ideológicos, mm..., en mi opinión, conllevan a tener que tener un estilo de vida cercano a estos conceptos. [...] Esto te conlleva tener una cierta moral, sobre tu..., sobre tu vida y sobre tus comportamientos en la

45 Entrevista a Dolors Igual.

46 Entrevista realizada por Joel Sans a Enrique Pérez Cañamares (dirigente de la OIC en Madrid y en el ámbito estatal), Valencia, 22 de junio de 2016. 
vida. Es posible decir que yo me voy de vacaciones cuando hay unas reuniones importantes o una huelga o un no sé qué, pues esto es... es incompatible. [...] Se exige una moral, una moral revolucionaria, de entrega -exagerando, eh?, un poco-, de entrega total a la causa, no? [...] Y esa entrega no solamente te afecta a ti, afecta a ti y a tus bienes, eh? Afecta a ti y a tus bienes. Entonces yo creo que [...] fue una moral muy fuerte y unos planteamientos ideológicos muy duros, muy duros. ${ }^{47}$

Esta cultura militante conllevaría dificultades importantes para hacer un balance entre la esfera política y la personal y tendría, en bastantes casos, efectos en una compresión de esta última. En este sentido MuñozSaldaña plantea en un estudio sociológico que este modelo de compromiso llevaría incluso a una «alienación militante», ya que el tipo de política finalista revolucionaria provocaría un distanciamiento del presente y las formas de lucha tendrían un valor no por ellas mismas, sino como medios para el objetivo a conseguir:

Muchas veces en el camino hacia la "liberación" de un mundo sin alienación, los militantes terminan presentando rasgos de alienación en su propia subjetividad, lo que llamamos la "alienación militante”. Se presenta una lógica sacrificial de anulación del “yo", un distanciamiento de los “otros” compañeros quienes poseen "menor consciencia” que los militantes, además de una separación con la llamada "vida personal", por nombrar sólo algunas características. Esto finalmente termina distanciándolos de la utopía propuesta, no llevando a cabo hoy el mundo que se quiere para mañana. (Muñoz-Saldaña 2013)

En el análisis que hace Muñoz-Saldaña habla también de otro tipo de militancia, más de matriz libertaria, que pone el énfasis en una emancipación en el propio presente y que se contrapone al que podríamos llamar "ortodoxo comunista":

47 Entrevista realizada por Joel Sans a Toni Pons (dirigente de COC-OIC en Mallorca y Córdoba), Córdoba, 9 de marzo de 2016. 
La tendencia a comprender el accionar político como un fin en sí mismo, poniendo especial cuidado en el "cómo" se llevan a cabo las relaciones sociales. Esto podríamos decir que corresponde a lo que Graeber llama "políticas prefigurativas", es decir, donde no importa la visión utópica que se tenga del futuro, sino más bien el compartir formas básicas no-autoritarias en el presente, para construir hoy la sociedad que queremos. (Muñoz-Saldaña 2013)

Hay en lo que comenta este autor buena parte de verdad. De hecho, el concepto de «alienación militante» es muy ilustrativo y sugerente. La propia adscripción al partido y la causa terminaría relegando a un segundo plano una parte del espacio vital de la persona. Esto es algo que pasó en distintos grados y que es explicitado en determinadas entrevistas, donde se señala el alto peso que tenía el sistema de creencias ideológico en la propia vida y la gran dedicación de tiempo, lo que obligaba a dejar de lado otros aspectos. La idea del sacrificio militante, de hecho, asume que hay aspectos de uno mismo y de la vida que hay que dejar de cultivar, que hay que arrinconar o supeditar, en pro de la causa. Sin embargo, este tipo de compromiso y modelo de vida, si bien había unos roles incentivados por la organización y su cultura política, se tomaba voluntariamente y era asumido por el propio militante, aunque seguramente este no fuera muy consciente de que podía estar operando este tipo de reducción vital.

Los testimonios de antiguos militantes ilustran justamente las dificultades del balance entre la implicación política y otros aspectos vitales. La experiencia de Joana muestra esta «alienación» en el hecho de que la militancia política empezó como una manera de dar forma a unas inquietudes personales, pero estas terminaron relegadas y se produjo una escisión entre ambas cuestiones:

Jo començo pel tema més personal. Lo que passa que después la part personal la deixo estar i em poso a tope allà amb la part política i això va ser un cost important. O sigui, va arribar un moment que [hi] va haver un trencament entre la part més personal i la part política, i d'alguna forma la part personal la sacrifiques en funció de la política... Tenia un cost important. ${ }^{8}$

48 Entrevista por videoconferencia a Joana.

DICTATORSHIPS \& DEMOCRACIES 6 (2018) · EISSN: 2564-8829 · PUNCTUM, UNIVERSITAT OBERTA DE CATALUNYA \& FUNDACIÓ CARLES PI I SUNYER 
De ello no se dio cuenta en los momentos de gran actividad:

en aquells moments estaves a la voràgine de... Semblava que lo que estaves fent tenia sentit i que valia la pena, perquè hi havia molta gent i a més la dictadura pues ja estava tal, i sembla que s'anava a obrir un procés nou. I jo què sé. En aquell moment no t'ho planteges: a lo millor comences a sentir un buit, comences a sentir per dintre que algo no va bé però no no no, va ser molt posterior. ${ }^{49}$

Esa relegación de aspectos personales que estaban pasando factura por dentro, pero sin poca consciencia de ello, no emergería hasta el momento de la Transición, como también pasaría en muchos otros militantes, lo que conllevaría una crisis de militancia.

Koldo Tapia explica cómo ese modelo de entrega total ya lo había vivido previamente en la organización católica y obrera juvenil Herri Gaztedi, donde la organización pasaba por delante de todo: «nuestro corsé era el compromiso, con quien nos debíamos por encima de nuestra libertad personal $» .^{\circ}$ Cuando entró en la OIC, era más consciente de intentar conseguir un balance entre los aspectos personales y la militancia, algo que era muy difícil por el ritmo de trabajo y todas las responsabilidades en comités:

La coyuntura era muy exigente: el ritmo de los acontecimientos era tal que, un ritmo de actividad y los que necesitábamos leer mucho, tenías que meter más horas que un tonto. Y cuando teníamos los pájaros locos que no paraban de escribir, [...] cierto que hubo una gran dificultad para tu propio autodesarrollo. ${ }^{51}$

Ferran Saro, militante obrero de la OIC en Santa Coloma, cuenta cómo el compromiso político le llevó a tener una menor implicación hacia sus dos hijos, algo que a posteriori ha visto críticamente: "Jo súper polititzat, dedicant menys temps als temes familiars, no? Això és un dels meus errors, no?». Una anécdota suya ilustra la enorme focalización mental en lo político. Cuando nació su segundo hijo estuvieron dos o tres días en el

49 Ibídem.

50 Entrevista realizada por Joel Sans a Koldo Tapia (dirigente de la OIC en Euskadi y líder obrero en la Babcock Wilcox), Urnieta (Gipuzkoa), 9 y 15 de diciembre de 2014.

51 Entrevista a Koldo Tapia. 
hospital y después llevaron al bebé a casa, pero él no llegó a subir porque fue directamente a una reunión de la Asociación de Vecinos:

Arribem a casa i jo, encara abans de pujar, me’n vaig a una reunió per preparar la verbena, tu! O sigui, jo no pujo a casa meva! Arribo al barri, deixo la meva dona i me'n vaig! [...] O sigui, això és increïble, no? O sigui, estava tan... Però és clar, la verbena s'hagués fet igual, eh? [...] Tan important tenia que ser que jo anés allà a preparar un tema de l'Associació? [...] Però clar, encara era allò de que per sobre de tot —nosaltres, jo—, era el tema polític, el tema de la consciència obrera, el tema de la responsabilitat collectiva... Era, era molt gran! ${ }^{52}$

Incluso el tema de la reunión no era muy importante, pero ilustra muy bien el sentido de compromiso y responsabilidad política que se tenía y que pasaba por encima de aspectos personales y vitales como estar con un hijo. Ferran no se arrepiente de sus ideales, pero sí que es crítico con el balance del tiempo:

O sigui, masses reunions per masses coses i per repetir. I aquestes reunions moltes eren temps, no? Però el temps que vaig deixar de dedicar als meus fills quan eren petits, això és insalvable. No ho pots salvar, no? Llavors els meus fills han patit masses canguros.

Ferran Saro fue militante en la OIC hasta 1977, aproximadamente, y dos años después entró al PSUC. El cambio de época que marcó el inicio de la democracia le llevó a continuar en la política, pero con una perspectiva que suponía un giro respecto al modelo de militancia total de los años setenta, un modelo que, como hemos dicho, conllevaba una gran disciplina y problemas de consciencia si se fallaba en las tareas asumidas:

La dedicació anterior, en els anys, diríem en els anys setenta, la dècada dels setanta, era una exclusivitat a la política i a la lluita, i el compromís era al 10o\%.

52 Entrevista realizada y transcrita por José Manuel Hidalgo Ramírez a Ferran Saro Madrilejos (militante obrero de la OIC en Santa Coloma de Gramenet), del 13 de diciembre de 2001 al 10 de mayo de 2002. Fundació Cipriano Garcia - Arxiu Històric de la CONC (AHCONC), fons d'Història Oral i Militància Sindical. Biografies Obreres (1939-1978). 
Per sobre de tot, eh! Era una cosa!... Era la militància, no? Saps? No sé, era com una cosa de disciplina, no? Fins i tot tenies problemes de consciència si fallaves a una reunió. Problemes... Saps? Era com un patiment, no? Eres, eres feliç perquè era lo que volies i perquè era la realització collectiva en el canvi, etc., etc. Després quan es normalitza en democràcia i tot, clar, jo també faig un canvi, no? Per exemple, els temes d'esports, no? A mi la política em va treure l'esport. Després un altre cop he tornat a ficar-me en l'esport.

L'estat polític va passar a no ser el centre en el qual girava tota la meva vida. Però sense un desencantament!, no? Sense dir «no, escolta...», sinó que és un canvi de prioritats, no? [...] Vist des d'ara... En aquell moment no! [...] però vist des d'ara és que era una passada.

Ferran Saro hizo un cambio de prioridades en que la política bajó del lugar que ocupaba hasta el momento, lo que le permitió recuperar actividades que eran importantes para él, pero que había dejado por la militancia, como el deporte.

Toni Pons, militante de la OIC en Mallorca y Córdoba, también explica cómo la involucración militante le supuso, ya en el seno de la JOC, dejar unos estudios de piano que le llenaban en buena medida y que habían sido una de sus motivaciones, juntamente con la política, para mudarse de Mallorca a Barcelona. No recuperaría la práctica del instrumento hasta muchos años más tarde, después de jubilarse. ${ }^{53}$

Otro militante, Jorge Núñez, Secretario General de las Juventudes de la OIC, dejó la militancia a los inicios de la democracia al mismo tiempo que recuperó el teatro (de hecho, llegaría a ser más adelante un reconocido actor):

Yo había tenido que abandonar la Escuela de Arte Dramático y todo eso por la militancia, y dije «pero si donde realmente yo soy feliz y donde me siento creativo y donde encuentro el sentido de la vida es dedicándome a cuestiones artísticas». ${ }^{4}$

53 Entrevista a Toni Pons.

54 Entrevista a Jorge Núñez. 
Andoni Etxebarria, un líder obrero de la OIC de Euskadi, hace una valoración global crítica de cómo el comportamiento militante afectaba en su caso a las relaciones personales y ve hoy con ojos distintos cómo tendría que ser la relación entre las creencias y la parte vivencial:

Otro de los grandes problemas de la época, las vidas de relaciones personales eran... no existían, eran casi inexistentes, mm... Nuestra... - yo hablo por mi, eh? -, nuestra gran dedicación era... dedicación a la causa, mm... Entonces, con lo que era la pareja o... siempre estaba la causa por medio, eh? Si no estaba la causa por medio, la pareja de uno era un estorbo, eh? [...] Era un vivir para la causa sin vivir para la vida o algo así, mm... Aunque la vida sí está en la causa, pero, para que... Pues yo de allí saco la conclusión de que... la causa, de las creencias, es una pata para caminar, pero si la parte humana, la vivencial, no la llevas pareja a ella o no va por delante de ella, pues, bueno, a la larga no funciona, no resuelve, sí. Una sociedad libre, eh..., necesariamente no va a ser una sociedad política, mm..., será antes una sociedad humanizada. Es decir, la solidaridad, ah... que salga por dentro, que sea vivencial, que viva la persona, no por criterios, sino por sentimientos. ${ }^{55}$

También hay militantes, como Rodolfo Ruiz Ligero, que mantendrán la prioridad en la política y en el activismo social después de la Transición y prácticamente hasta la actualidad. Una decisión asumida sin reparos, aunque ello haya significado desarrollar menos su faceta artística como director de teatro. Y también uno de los dirigentes de la organización en Valencia, el abogado laboralista Vicent Álvarez, mantuvo un espacio de tiempo propio para el ocio cultural que no era muy habitual entre la militancia. ${ }^{56}$ Sin embargo, hay una parte significativa de testimonios que muestran una compresión de los aspectos personales.

¿Cómo se puede explicar que se produzca esta alienación militante en organizaciones que justamente propugnan la liberación social? A mi en-

55 Entrevista realizada por Joel Sans a Andoni Etxebarria (líder obrero de la OIC en Vitoria), Zumaia, 12 de diciembre de 2014. Entrevista citada bajo seudónimo.

56 Entrevista realizada por Joel Sans a Rodolfo Ruiz Ligero (militante y dirigente de la OIC en Madrid), del 12 de junio al 13 octubre de 2015, y entrevista realizada a Vicent Álvarez (abogado laboralista y dirigente de la OIC en Valencia), Valencia, 23 de junio de 2016. 
tender hay una suma y mezcla de factores. El contexto político, con el régimen franquista, al que se quiere derrocar, y el hecho de estar viviendo un auge de luchas que proporciona ánimo y da una perspectiva de final cercano del régimen, son aspectos que refuerzan la importancia dada al compromiso. Es fundamental la vivencia de la movilización, que tiene un componente emocional significativo con luchas y victorias tanto simbólicas - la ocupación del espacio público y la conquista de espacios de libertad (Domènech 2002) - como materiales i en las que se experimenta la solidaridad, la unión o la fuerza que había en la capacidad colectiva de organizarse y de enfrentarse a la dictadura y a los patrones. Por ejemplo, las asambleas de miles de estudiantes en la universidad o la lucha vecinal daban mucha fuerza y llevaban a pensar que el cambio era posible y estaba cerca:

Al barri d'Orriols, l'associació de Veïns tenia poderío, però poderío. És que se reunien els presidents de les associacions de veïns i paraven... jo que sé!, en València lo del llit del Túria, que volien fer una autovia en el Túria - lo que és ara... que és un jardí-, i se parava [...]. Era un contrapoder, saps? I era un contrapoder molt radical i que veies que no era una fantasia de... no era una cosa de fantasia de quatre estudiants, no no. ${ }^{57}$

En este contexto pesa también la experiencia de la represión y de la clandestinidad, frente a la cual se requiere una ética de sacrificio (Domènech 2009, 122). La propia propuesta política, de carácter finalista, tiene visos de supeditar el presente y la práctica actual al objetivo. Ante la idea de la revolución mundial cercana - con cierto razonamiento teleológico de que la historia se dirige hacia allí y de que se tiene la historia a favor-, la vida personal aparece como algo secundario. Ligado a esto, hay un sistema de creencias muy vertebrado, proveído por el marco teórico de la organización y por su cultura política, que da una explicación del funcionamiento del mundo y que tiene una propuesta potente de cambio global, de acción y de militancia. Este sistema de creencias proporciona un convencimiento mental grande respecto al compromiso político que 
se está practicando. Como diría en relación con el PCE el poeta Marcos Ana: «la seguridad en la fuerza de las ideas del comunismo y en la justeza de su causa, alienta la resistencia de los comunistas en las cárceles franquistas» (Domènech 2009, 123).

Finalmente, más allá de la esfera puramente intelectual-mental, actúan otros mecanismos distintos. Uno de ellos es la sacralización de ciertas concepciones políticas como el propio marxismo, o la idea de la revolución y del partido como algo indispensable para transformar el mundo. De hecho, los mitos políticos y determinados lemas, aunque parten de un concepto, tienen en su uso un componente emocional que opera más allá del componente racional. Otro mecanismo es que se puede producir una cierta transferencia del ego personal —el ego entendido como construcción del yo- al ego colectivo de los marcos organizativos a los que se pertenece: el partido o, en menor medida, los espacios de los movimientos sociales. Un ego colectivo que permite superar aspectos de individualismo y egoísmo, y, por lo tanto, actuar desinteresadamente, sin motivaciones de mejora directamente personales, pero que al mismo tiempo crea una dinámica de comportamiento grupal con nuevas identificaciones colectivas y de compromiso hacia la organización y de defensa de ella que puede ser también muy fuerte. Elementos como el orgullo, la defensa de lo propio, el creer tener la razón, entre otros, que actúan a nivel individual como refuerzo egoico, pueden pasar entonces a actuar a nivel colectivo, con el consecuente afloramiento del sectarismo, visto anteriormente.

El proceso de creación de una identidad político-ideológica, de realizar una identificación con la organización y una inmersión en su cultura política, son los vectores de esta transferencia de lo personal hacia lo colectivo que sirve para crear una autoimagen de quién se es. De hecho, la cultura política de la organización - concepto que engloba algo más que la ideología y las propuestas políticas (estratégicas y tácticas) - proporciona un aprendizaje de actitudes y pautas de comportamiento a la persona (Pérez \& Sierra 2010, 20-31). Además, ayuda a una identificación con el hecho de ser militante, obrero, anticapitalista o revolucionario, que define la propia persona, que refuerza el sentido psíquico de uno mismo, a partir de algo exterior, en este caso colectivo. La configuración de una identidad militante es un aspecto de ello. Como explica la militante 
del MC Núria Casals: «Costa molt construir-se una identitat i quan te la fas costa una miqueta renunciar-hi. Me'n vaig adonar, de les fidelitats».58

Dar una gran importancia al marco colectivo con el que uno se identifica, y reforzarse personalmente a través de él, puede implicar ir en detrimento de determinados aspectos del propio individuo. Como señala Domènech, para el caso del PCE, la inserción de la persona en una identificación da fortaleza, ya que el soportar la militancia en situaciones duras «sólo se sostiene a partir de una ubicación del yo en un pasado de tradiciones fuertes». En la nueva vida militante «el yo se diluye en el nosotros, un nosotros entendido como los comunistas y, más allá, como el "pueblo". Este nuevo yo tiene un pasado, una tradición común que identifica los signos de identidad histórica que son propios de este nosotros» (Domènech 2009, 118). También cabe añadir en este punto que la compleja relación persona y colectivo, en que ambos se dan forma mutuamente, en el caso de la militancia se da bajo el paraguas de lo político. Y esto conlleva unas parcialidades determinadas, se genera un espacio de concentración muy acotado, una región prácticamente unidimensional, la política, que relega las otras. Sin embargo, la materia prima del colectivo, que es el individuo, continúa teniendo más dimensiones que la política, aunque estas otras no estén potenciadas por el marco político-organizativo, por lo que aquí se pueden generar disonancias entre lo personal y el marco colectivo.

Dicho esto, y asumiendo que este tipo de militancia revolucionaria podía llevar a tener matices de «alienación», cabe mencionar que también hacía crecer a la persona en empoderamiento, en capacidad de acción y organización, y en formación intelectual, entre otros aspectos. Hay un aprendizaje vital a la par que político:

La entrada a la militancia comunista durante este período [...] supone la entrada a un sistema de valores, a una lectura del pasado, del presente y del futuro. Supone en este sentido un cambio vital de primer orden en lo que respecta a la lectura de la realidad y del autorreconocimiento en ella. (Domènech 2009, 117)

58 Entrevista realizada por Joel Sans a Núria Casals (militante obrera del MC en Barcelona), Barcelona, 2 de julio de 2013 . 
Como dice Enrique Pérez Cañamares, la militancia daba sentido y posición a la persona y, a la vez, una mayor comprensión del mundo:

No podías ser inmune a lo que estaba pasando en los últimos años del franquismo, ni mucho menos. Tenías que tomar posiciones, no? Ahora, pasar el franquismo, del antifranquismo, a posiciones más [radicales]... pues ya un poco depende de la oportunidad que tenga la gente de formarse, de pensar, de relacionarse, no? En este sentido yo creo que ese aprendizaje humano tuvo unas partes muy buenas: eres capaz de entender el mundo..$^{59}$

En general, el recuerdo que se transmite en las entrevistas para este tipo de práctica militante es positivo, de haber hecho algo que era necesario hacer. Hay aspectos que se ven críticamente e incluso me he encontrado con un exmilitante de la OIC que ha rehusado hablar de su pasado de implicación por tener un mal recuerdo de ello; se trata de un perfil existente, ciertamente, aunque muy minoritario.

Cabe tener en cuenta, asimismo, que es habitual en el recuerdo otorgar una preeminencia positiva al pasado. Es algo que encontramos de forma similar en los estudios sobre el PCE: «La militancia política — con su doble y ambivalente sentimiento de amputación o alienación personal y enriquecimiento-, parece percibirse por los antiguos militantes más en esta segunda dimensión que en la primera» (Erice 2009, 182).

También el estudio sobre la autopercepción de los antiguos militantes del PCE a partir de sus testimonios muestra que se considera que «la militancia pudo arrebatarles años de libertad, la posibilidad de una vida familiar normalizada o de una actividad satisfactoria, pero les proporcionó un sentido y una identidad a su existencia relacionados con valores elevados» (Erice 2009, 183).

Por ejemplo, Ferran Saro no se arrepiente de sus ideales, pero sí es crítico con el tiempo que dejó de dedicar a la familia, algo común en otros casos. Otro testimonio de Vitoria hace balance de la militancia y habla de cómo esta reducía aspectos de la persona: 
Mi pasado militante me ha dado valor y ha debilitado mi grado de afectividad, eh. La militancia en un contexto... es una situación dura, y o te pones a las duras o no te pones. Y cuando estás en la barricada [ríe], cuando estás en la barricada, la trinchera [...]. Me ha dado valor, sí, bueno, conocimientos a un nivel, pero me ha hecho creer también que soy... que tengo conocimiento más de lo que creía tener, mm... Y cuando uno cree saber más de lo que cree, entra la parte de la ignorancia y eso es muy peligroso también. Y la ignorancia puede ser muy dañina, porque cuando uno cree, en su ignorancia, que tiene la verdad, y cuando uno cree que está en la posesión de la verdad, hostia puta, puede hacer cualquier barbaridad, eh? ${ }^{60}$

Los dos tipos de actitudes militantes que comenta Muñoz-Saldaña estuvieron presentes y marcaron una cierta polarización entre un compromiso militante más estricto, basado en una actividad política estructurada en la organización y en una disciplina importante, y otro estilo más hippie o menos encuadrado, centrado en el cambio en las formas de vida y en dar autonomía a la persona o a los colectivos en cuanto al estilo de vida. El primero pondría el énfasis en la liberación social y política a gran escala, del conjunto de la clase; y el segundo, en el cambio y la liberación personal o grupal, con prácticas de vida alternativas. Sin embargo, la separación entre ambos no sería tan marcada, sino que habría puntos de cruce. En cierta manera, los dos componentes son dimensiones del mismo momento de efervescencia de alternativas. En el caso de la OIC, la política, aunque buscara el objetivo finalista de la revolución, planteaba cuestiones de medios en que se les daba un valor: la autoorganización y la democracia obrera eran cuestiones por implantar ya en el presente y no eran una abstracción, pues ligaban bien con las experiencias huelguísticas radicales del momento. Por otro lado, en cierta manera en consonancia con el ideal comunista y el ambiente colectivo que se expresaba en la movilización social, se hacían un tipo de prácticas que potenciaban un tejido comunitario (Gómez 2018). Y, aunque no formara parte de la política de la organización propiamente dicha, en una parte de la militancia se encontraban intentos de cambiar las formas de vida del presente, a pe-

6o Entrevista a Andoni Etxebarria. 
sar de que no fuera reivindicado o teorizado de forma abierta. La militancia recibía la influencia de otras actitudes y estilos de vida presentes en el momento, y las podía asumir, aunque no fueran completamente acordes con la moral comunista obrera y austera existente en la organización, en una suerte de militancias cruzadas o de identidades complejas que integraban distintos elementos. Veamos algunos ejemplos de ello.

El testimonio de Dolors Igual muestra intentos de hacer cambios en las relaciones sociales y de vida inmediatos, a través del feminismo, con grupos de trabajo en la universidad y también con el cierre de un psiquiátrico:

És que era, era, una ebullició constant. I llavors jo a vegades pense, clar, és que jo lo que era, era una diletant, eh?, perquè anava a tot, anava a les jornades de dones, fèiem grups de dones per a contar-nos històries, a la vegada [...] vam començar a fer avortaments illegals amb un ginecòleg [...]. Van obrir el psiquiàtric i la gent del psiquiàtric se n’anava a viure... vam voler tancar els psiquiàtrics, lo de l'antipsiquiatria, i llavors van tancar... i nosaltres vam fer una assemblea en Benimaclet, que era el barri on vivia i nos vam endur a un parell de tipos del psiquiàtric a viure amb nosaltres que no van voler vindre.

Dolors Igual recibió el influjo del cambio de la vida cotidiana a partir del movimiento estudiantil y de la influencia del movimiento feminista, que fue fundamental para ella. En su caso, la subversión política iba de la mano de cambiar las formas de relacionarse:

No és que anàrem políticament només, sinó que era una forma de canviar les relacions... Doncs això, en la universitat el professorat que estava en un grup de treball, anaves al barri i hi havien grups de dones i venia una [...] que va començar l'autoexploració, [...] o l'avortament, que se feien... era molt variat. ${ }^{61}$

Había a menudo una práctica comunitaria. Lourdes Ponce explica cómo en el piso que compartía con otros jóvenes tenían un fondo común donde ponían íntegramente su sueldo y cada persona cogía según sus necesida- 
des. Además, cuando había problemas, hacían una asamblea. ${ }^{62}$ También Ana de Madrid vivió en pisos parecidos a una comuna con otros militantes, con los que compartía toda la comida y el dinero. Sin embargo, ello chocó con la dirección de la organización, a quien consideraba demasiado abierta en relación con las necesidades de seguridad. ${ }^{63}$

En cualquier caso, las situaciones económicas difíciles de los militantes y los cambios habituales de domicilio por motivos políticos o para hacer frente a la persecución, llevaban de forma frecuente a compartir pisos y a acoger a militantes. Había toda una camaradería en la que era usual compartir recursos. Incluso en Córdoba hubo un debate en el seno de la OIC en el que se planteaba que las bibliotecas privadas se pusieran a disposición del partido, algo que no fue bien recibido por todo el mundo. ${ }^{64}$

Ferran Saro, militante obrero de la OIC en Santa Coloma, también explica que había una concepción colectiva de los bienes personales, no solamente entre los militantes, sino que también formaba parte del tejido social del momento:

Nosaltres, en principi, érem en contra de tenir cotxe... El primer cotxe, un 6oo, el comprem entre dues famílies i el compartíem, per entendre'ns. [...] Jo compro una moto de segona mà, una vespa. La tinc allà a la +++ del meu bloc i aquella moto, [hi] havien quatre o cinc famílies que sabien que era per tots i llavors tenien clau i el primer que l'agafava, l'agafava, no? [rialles de fons] $\mathrm{O}$ sigui, que teníem una certa concepció de collectivitat i de no tenir propietat.

Del mismo modo, la crianza de los hijos se compartió entre varias familias del barrio:

[...] experiència enriquidora de compartir els fills amb vàries parelles, etc., no? I vam fer un creixement els primers... tant la meva filla com el fill. Veure'ls créi-

62 Entrevista a Lourdes Ponce Noria.

63 Conversación y entrevista por correo electrónico con Ana (militante en los inicios de la OIC en Madrid), 25 de febrero y 1 de marzo de 2017.

64 Entrevista realizada por Joel Sans a Pepe Larios (líder vecinal y de la OIC en Córdoba), Córdoba, 9 de marzo de 2016. 
xer en un petit entorn de 4 o 5 parelles del barri que tenim els fills a la mateixa època i per tant casi expressament! [...] Per tant en els primers anys creixen junts.

Ferran Saro se casó en el año 1972. La forma como realizaron la boda muestra muy bien las actitudes del momento. No hicieron convite, no aceptaron regalos ni tampoco quisieron fotografías. Su planteamiento de pareja era empezar desde cero en un piso de alquiler:

Nosaltres fem un casament en què volem començar de zero i, per tant, no acceptem regals, no? Una cuina, una taula i un llit, i a partir d'aquí comencem a viure, no? No volem regals. Ara no faria el mateix! [rialles de fons]. T'ho dic sincerament! No volíem fotografies! +++ Allò era una espècie d'actitud anticonsumista... tot lo que tu vulguis, no?, fruit de, no sé, d'això del 68 i tot allò, no? Idealistes, com tu vulguis!, no?

La ceremonia de boda fue oficiada por un cura obrero y se convirtió en una especie de asamblea donde los asistentes incluso discutieron el sentido del matrimonio:

[Hi] Havia gent de tots els partits polítics, no? [El oficiante:] «Pero aquí pido respeto porque aquí vamos a hacer una asamblea cristiana y, por tanto, en esta asamblea, pues yo voy a dar la palabra y que todo el mundo intervenga». Llavors la gent va començar a aixecar la mà i es va fer un debat [...] O sigui, per què ens casàvem? Si estàvem a favor, estàvem en contra, de si això era... Si casar-se o no casar-se, no? I al final, doncs nosaltres vam dir «bueno, nosaltres acceptem tot això, ho respectem i hem decidit casar-nos i tal. Aquí tenim un testimoni». I això va ser la cerimònia! ${ }^{65}$

La familia de la mujer, que había venido especialmente para la ceremonia desde Jijón, tuvo la sensación de vivir un show y de que su hija no había llegado a casarse. Este testimonio es muy gráfico de cómo las actitudes de cambio y transgresión sacudían situaciones incluso tan definidas socialmente como una boda.

65 Entrevista a Ferran Saro Madrilejos.

DICTATORSHIPS \& DEMOCRACIES 6 (2018) · EISSN: 2564-8829 · PUNCTUM, UNIVERSITAT OBERTA DE CATALUNYA \& FUNDACIÓ CARLES PI I SUNYER 


\section{Conclusiones}

A lo largo del artículo hemos visto la complejidad de la relación entre vida y política. La militancia revolucionaria - con bastantes aspectos compartidos con el espectro más amplio de la izquierda - nutría unas inquietudes de carácter vital o articulaba unas necesidades materiales o sociales; ofrecía una comprensión del mundo; definía el lugar o la posición de la persona en la sociedad; daba unos objetivos de transformación de la realidad; dotaba de un tipo de praxis, y proveía de una organización o marco colectivo desde donde desarrollar estos aspectos, que proporcionaban fuerza y sustento a la persona. De esta forma lo político iba mucho más allá de un marco ideológico, creando una forma de sentir y de ser.

Las organizaciones revolucionarias, y en este caso la OIC, recogieron los anhelos y sentimientos de personas que querían enfrentarse al franquismo y a las situaciones de injusticia social, al mismo tiempo que se enlazaban con el ambiente del momento, de creciente oposición a la dictadura. Estructuraron la actividad práctica política y social bajo un prisma ideológico marcado, una visión del militante como combatiente y un determinado modelo de partido influido por su interpretación del leninismo y de la moralidad de una organización obrera y comunista; ello configuraba una determinada cultura política y militante, y una identidad propia con elementos específicos en la OIC - como el marxismo heterodoxo, el consejismo y el radicalismo obrero-, pero también con muchos puntos en común con el resto de organizaciones. La concepción política de la OIC llevó a sus militantes a buscar un importante rol de liderazgo en la movilización social y en la lucha política, y a asumir la tarea de cambiar de forma revolucionaria el sistema capitalista - intentando influir en la realidad sobreestimando en buena medida las propias capacidades- Esta perspectiva, de enorme responsabilidad, conducía a una ética de sacrificio que potenciaba la implicación y dedicación militante.

La concepción de los COC-OIC de una militancia de alta intensidad fue cambiando entre 1971-1972 y 1977. En los últimos momentos se fue reduciendo en cierta medida el intervencionismo sobre la vida personal, algo que mostraba la evolución de la organización y el cambio de contexto conforme se acercaba el fin de la dictadura. Aun así, se mantenía una gran 
entrega vital en términos tanto cuantitativos (de horas dedicadas o de implicación material) como cualitativos: una política que impregnaba gran parte de la vida de las personas militantes; esto es, que configuraba un estilo de vida y unas motivaciones que politizaban las relaciones sociales y también afectaban decisiones vitales como el sitio donde vivir y el trabajo.

La militancia política de los años setenta llenó a las personas, al proporcionarles un sentido a la vida, una descubierta del mundo y un aprendizaje, coincidiendo en la mayoría de ellas con el inicio de la juventud. Pero en una suerte de paradoja, este mismo compromiso y actividad política efervescente que llenaba la vida de los individuos, también la reducía alrededor de lo político, comprimiendo en muchos casos la dimensión vital. Así, la política revolucionaria canalizaba los anhelos de libertad, justicia y transformación social, muy presentes en la juventud del momento, pero los estructuraba bajo una propuesta que encorsetaba también estos deseos hacia un sistema de creencias y una praxis muy absorbente y en buena parte delimitada. Había una dualidad entre empoderamiento y alienación de partes de la persona. La primacía de la causa, el socialismo y la revolución, y de la organización revolucionaria (como elemento clave de la lucha por la causa) conllevaba poca atención a las mismas personas militantes, algo que fue vivido sin problemas en algunos casos, pero que en otros implicó situaciones duras de desgaste a nivel personal.

Este compromiso y modelo de vida, si bien estaba potenciado colectivamente por la organización, se tomaba voluntariamente y era asumido por el propio militante. En algunos casos, el ritmo de actividad hizo que no se fuera muy consciente de que podía estar operando este tipo de reducción vital, como indica la experiencia de Joana; en otros casos, se asumía por no haber mucho margen de maniobra, como es el caso de Koldo Tapia.

Los testimonios reflejan esta ambivalencia, si bien hay una gradación según la persona en la visión crítica o positiva sobre su pasado militante. Al mismo tiempo, y como parte del ambiente del momento, los militantes de las organizaciones también llevaron a la práctica cambios en sus formas de vida asociados a los ideales políticos, promoviendo experiencias de compartir bienes de forma comunitaria o llevando la práctica de las asambleas y la democracia directa incluso a una boda. 
Todo ello nos muestra la riqueza y la complejidad de las vivencias de compromiso militante de los años setenta, nutrido de muchos ingredientes distintos, y también las contradicciones que se desarrollaron en el momento entre el ideal, la praxis realizada y, finalmente, los resultados conseguidos, bastante lejos de la transformación revolucionaria que se perseguía. De esta forma, la militancia se desarrolló entre los problemas del encorsetamiento personal y el valor y la fuerza de la pasión militante, de atreverse a salir de los límites establecidos por el franquismo y de perseverar en lo que se creía, ante unas condiciones muy difíciles de represión, para dar la vuelta a la asfixiante situación política y social que se vivía. Con ello quedó una movilización, unas experiencias y unas emociones que - como muestra la vivacidad de los testimonios - tuvieron un peso decisivo en hacer crecer estas personas - con todos los matices que esto implicó- y conformarlas hasta el presente.

\section{Bibliografía}

Alted, Alicia, y Abdón Mateos. 1990. «Problemas de método en el estudio de la oposición al franquismo. La utilización del testimonio oral». Espacio, Tiempo, Forma 3/V: 5768. http://revistas.uned.es/index.php/ETFV/article/view/2724/2584. doi: https:// dx.doi.org/10.5944/etfv.3-2.1990.2724.

Andrade, Juan Antonio. 2012a. «Con su propia voz. Los militantes de base ante el cambio ideológico del PCE y el PSOE en la etapa central de la Transición española». Historia Social 73: 123-143.

- 2012b. El PCE y el PSOE en (la) transición. La evolución ideológica de la izquierda durante el proceso de cambio político. Madrid: Siglo XxI.

Beorlegui Zarranz, David. 2016. «La experiencia del desencanto en el País Vasco (19761986): memoria, subjetividad y utopía». Tesis doctoral, Universidad del País Vasco Euskal Herriko Unibertsitatea.

- 2017. Transición y Melancolía. La experiencia del desencanto en el País Vasco (1976-1986). Madrid: Postmetropolis.

Box, Zira. 2006. «Las tesis de la religión política y sus críticos: aproximación a un debate actual». Ayer 62: 195-230.

Bueno Lluch, Manuel, y Sergio Gálvez Biesca, eds. 2009. Nosotros los comunistas. Memoria, identidad e historia social. Madrid: Fundación de Investigaciones Marxistas / Atrapasueños.

Caussa, Martí, y Ricard Martínez i Muntada, eds. 2014. Historia de la Liga Comunista Revolucionaria (1970-1991). Madrid: Viento Sur / La Oveja Roja. 
Domènech Sampere, Xavier. 2002. Quan el carrer va deixar de ser seu. Moviment obrer, societat civil i canvi polític. Sabadell (1966-1976). Barcelona: Publicacions de l'Abadia de Montserrat.

. 2009. «Cenizas que ardían todavía. La identidad comunista en el tardofranquismo y la transición». En Bueno Lluch \& Gálvez Biesca 2009, 93-138.

Erice Sebares, Francisco. 2009. «El “orgullo de ser comunista”. Imagen, autopercepción, memoria e identidad colectiva de los comunistas españoles». En Bueno Lluch \& Gálvez Biesca 2009, 139-183.

Fundación Salvador Seguí, coord. 2018. Las otras protagonistas de la Transición. Izquierda radical y movilizaciones sociales. Madrid: Descontrol.

Ginard, David. 2009. «Sobre héroes, mártires, tumbas y herejes. Culturas militantes de los comunistas españoles (1939-1962)». En Bueno Lluch \& Gálvez Biesca 2009, 43-91.

Gómez Garrido, María. 2018: «Tejiendo solidaridad desde abajo: espacio social y construcción del sujeto colectivo en la izquierda rupturista», 60-71. En Fundación Salvador Seguí, coord., Las protagonistas de la transición. Izquierda radical y movilizaciones sociales. Congreso celebrado en Madrid, 24-25 febrero 2017. https:// congresotransicion2017.files.wordpress.com/2017/02/mesa-6-la-experienciamilitante_-memorias-y-trayectorias.pdf.

Harman, Chris. 1998. The fire last time. 1968 and after. Londres: Bookmarks.

Hernández, Jerónimo. 1976. El militante y la construcción del partido comunista, [s.1.]: OICE. Horn, Gerd-Rainer. 2007. The Spirit of '68. Rebellion in Western Europe and North America, 1956-1976. Nueva York: Oxford University Press.

Martín García, Óscar José, Damián González Madrid y Manuel Ortiz Heras. 2009. «Envenenando a nuestra juventud. Cambio de actitudes y bases de la militancia juvenil durante el segundo franquismo». Historia Actual Online 20 (otoño): 19-33.

Martín Ramos, José Luis, coord. 2011. Pan, trabajo y libertad. Historia del Partido del Trabajo de España. Barcelona: El Viejo Topo.

Martínez i Muntada, Ricard. 2016. «La izquierda revolucionaria en tiempos de cambio político. Algunas consideraciones generales y una experiencia particular», 141167. En Carme Molinero y Pere Ysàs, eds., Las izquierdas en tiempos de Transición. Valencia: Publicacions Universitat de València.

Morán, Gregorio. 1986. Miseria y grandeza del Partido Comunista de España, 1939-1985. Barcelona: Planeta.

Muñoz-Saldaña, Nicolás. 2013. «El énfasis en el "cómo" nos relacionamos/vivimos: la forma de vida en el tejido social como dispositivo biopolítico microgubernamental». XXIX Congreso de la Asociación Latinoamericana de Sociología, Chile. http:// actacientifica.servicioit.cl/biblioteca/gt/GT31/GT31_MunozSaldana.pdf.

Pala, Giame. 2013. «El militante total. Identidad, trabajo y moral de los comunistas catalanes bajo el franquismo». Cahiers de Civilisation Espagnole Contemporaine 10. https://ccec.revues.org/4642.

Pasajes, Felipe [Fernando Paniagua]. 2008. «Arqueología de la autonomía obrera en Barcelona, 1964-1973", 73-112. Espai en Blanc, coord. Luchas autónomas en los años 7o. Del antagonismo obrero al malestar social. Madrid: Traficantes de Sueños. 
Pérez Ledesma, Manuel, y María Sierra, eds. 2010. Culturas políticas: teoría e historia. Zaragoza: Institución Fernando el Católico.

Portelli, Alessandro. 1991. «Lo que hace diferente a la historia oral. Recuerdos que llevan a teorías». En Dora Schwarzstein, La Historia Oral. Buenos Aires: Centro Editor de América Latina.

Sans, Joel. 2013. «L'Organització d'Esquerra Comunista en el moviment obrer: les Plataformes i Comissions Obreres Anticapitalistes (1971-1977)». Carme Molinero y Javier Tébar, eds. VIII Encuentro Internacional de Investigadores del Franquismo. CDROM. Barcelona: CEFID / UAB / Fundació Cipriano Garcia de CCOO.

. 2016. «Desentrañar la militancia revolucionaria de los años 7o: el caso de la Organización de Izquierda Comunista». IV Encuentro internacional de investigadores del franquismo, Granada, 10 y 11 de marzo, inédito.

- 2017a. «Crisis de militancia en el cambio de ciclo de la transición: la experiencia de la Organización de Izquierda Comunista», 1545-1557. En Damián A. González Madrid, Manuel Ortiz Heras y Juan Sisinio Pérez Garzón, eds., La Historia, 'lost in translation'? Actas del XIII Congreso de la Asociación de Historia Contemporánea. Cuenca: Ediciones de la Universidad Castilla-La Mancha. http://seft. uclm.es/seft/resources/source/PDFs/La_Historia_lost_.pdf.

— . 2017b. «Militancia, vida y revolución en los años 70: la experiencia de la Organización de Izquierda Comunista (OIC)». Tesis doctoral, Universitat Autònoma de Barcelona. https://ddd.uab.cat/record/187368.

Teodori, Massimo. 1978. Las nuevas izquierdas europeas (1956-1976). Barcelona: Blume. Thompson, Paul. 1988. La voz del pasado: la historia oral. Valencia: Alfons el Magnànim. Wilhelmi, Gonzalo. 2016. Romper el consenso. La izquierda radical en la Transición española (1975-1982). Madrid: Siglo XXI. 